\title{
His-Tag-Mediated Dimerization of Chemoreceptors Leads to Assembly of Functional Nanoarrays
}

\author{
Elizabeth R. Haglin, ${ }^{\dagger}$ Wen Yang, ${ }^{\ddagger}$ Ariane Briegel, ${ }^{\dagger}$ and Lynmarie K. Thompson ${ }^{*},{ }^{\dagger}, \mathbb{C}$ \\ ${ }^{\dagger}$ Department of Chemistry, "Program in Molecular and Cellular Biology, University of Massachusetts Amherst, Amherst, \\ Massachusetts 01003, United States \\ ${ }^{\ddagger}$ Department of Biology, Leiden University, 2333 Leiden, The Netherlands
}

Supporting Information

ABSTRACT: Transmembrane chemotaxis receptors are found in bacteria in extended hexagonal arrays stabilized by the membrane and by cytosolic binding partners, the kinase CheA and coupling protein CheW. Models of array architecture and assembly propose receptors cluster into trimers of dimers that associate with one CheA dimer and two CheW monomers to form the minimal "core unit" necessary for signal transduction. Reconstructing in vitro chemoreceptor ternary complexes that are homogeneous and functional and

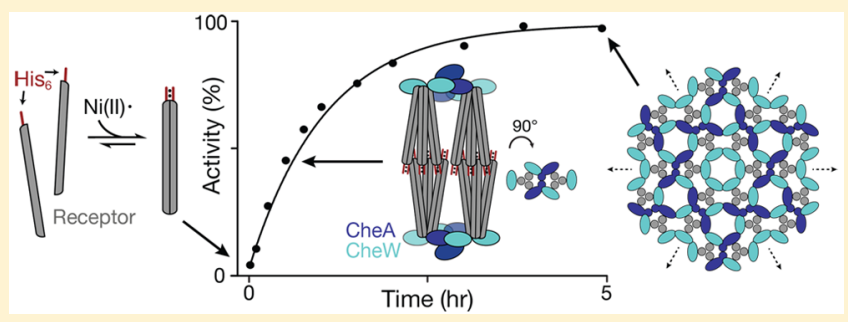
exhibit native architecture remains a challenge. Here we report that His-tag-mediated receptor dimerization with divalent metals is sufficient to drive assembly of nativelike functional arrays of a receptor cytoplasmic fragment. Our results indicate receptor dimerization initiates assembly and precedes formation of ternary complexes with partial kinase activity. Restoration of maximal kinase activity coincides with a shift to larger complexes, suggesting that kinase activity depends on interactions beyond the core unit. We hypothesize that achieving maximal activity requires building core units into hexagons and/or coalescing hexagons into the extended lattice. Overall, the minimally perturbing His-tag-mediated dimerization leads to assembly of chemoreceptor arrays with native architecture and thus serves as a powerful tool for studying the assembly and mechanism of this complex and other multiprotein complexes.

$\mathrm{M}$

any fundamental biological processes are performed by multiprotein complexes. ${ }^{1,2}$ To fully understand how these processes occur within the cell, methods are needed both for monitoring such processes in vivo and for isolation and/or reassembly of such complexes for in vitro structure-function analysis. Isolation and reassembly of complexes often require modifications or deletions of portions of the protein components: for instance, deletion of transmembrane domains of membrane proteins may be needed to prepare homogeneous complexes for structural or biophysical studies. Typically, such truncations also delete stabilizing interactions, and it becomes difficult to reassemble complexes with nativelike architecture and activity. We have developed a novel strategy for the stabilization of assemblies with native structure and activity for in vitro mechanistic studies.

Bacterial chemotaxis receptors are an ideal system for understanding the molecular details of signal transduction by membrane proteins and their complexes. Chemotaxis receptors are dimeric transmembrane proteins anchored in the inner membrane in large patches at the poles of the cell, which are responsible for sensing and responding to environmental stimuli. When the ligand binds to the receptor periplasmic domain, a signal is transmitted down the $\sim 300 \AA$ length of the receptor to control the autophosphorylation activity of an associated histidine kinase, CheA, which plays a central role in the signal transduction pathway. In addition to forming a complex with CheA and a coupling protein $\mathrm{CheW}$, receptors form large clusters (a membrane surface area of $53000 \mathrm{~nm}^{2}$ for Escherichia $c o l i)^{3-5}$ that enable extraordinary levels of cooperativity and sensitivity. ${ }^{6,7}$ The native system is built of trimers of receptor dimers that each form one vertex of a hexagon within the membrane and are stabilized at the membrane-distal tip of the receptor by hexagonal rings of alternating CheA and CheW. ${ }^{8-10}$ It is challenging to prepare homogeneous samples of functional chemoreceptor complexes in vitro for structure-function analysis. Complexes of the intact membrane-bound receptor with $\mathrm{CheA}$ and $\mathrm{CheW}$ are not homogeneous, in part because of the inability to control the orientation of the receptor within membrane vesicles ${ }^{11,12}$ or nanodiscs. ${ }^{13}$ In principle, the membrane orientation issue can be addressed by using a cytoplasmic fragment of the receptor, but this truncated construct does not form functional complexes with CheA or CheW in solution. Presumably, this is because the missing transmembrane and periplasmic domains are needed to provide protein-protein interactions that stabilize the receptor dimer and geometrical alignment within the membrane that promotes assembly of the array.

Received: July 21, 2017

Revised: August 21, 2017

Published: September 5, 2017 
In an elegant combination of membrane mimetics and nanoscale assembly tools, Weis and co-workers developed templating vesicles that promote the assembly of membraneassociated multiprotein complexes from soluble component proteins. This technology harnesses the high-affinity interaction between histidine imidazole groups and the $\mathrm{Ni}$ (II)-NTA functional group originally developed for immobilized metal affinity chromatography protein purification. ${ }^{14}$ The N-terminally His-tagged cytoplasmic fragment (CF) of the aspartate chemoreceptor binds to vesicles containing lipids with nickelchelating headgroups (DOGS-NTA), which enables binding of CheA and CheW into ternary complexes with kinase and methylation activity that mimic native signaling states. ${ }^{15,16}$ Molecular crowding agents such as PEG8000 provide an alternate means of driving assembly of functional complexes, with no requirement for membrane vesicles. ${ }^{17}$ Both assembly methods result in extended hexagonal arrays with nativelike architecture, $^{12}$ and PEG-mediated assembly forms sandwich lattices remarkably similar to cytoplasmic chemoreceptor arrays seen in some bacterial species. ${ }^{18,19}$

Here we report a novel method for assembling functional arrays in vitro and for monitoring the stages of assembly. We show that adding divalent metal salts to ternary mixtures of Histagged $\mathrm{CF}$, CheA, and $\mathrm{CheW}$ promotes receptor dimerization and assembly into active complexes with native stoichiometry and architecture. Moreover, kinetic analysis with this new assembly method provides the first experimental evidence that initial binding of CheA and CheW into ternary complexes proposed to be the "core unit" does not yield high activity, and that activity reaches its maximum upon formation of larger arrays. His-tag-mediated dimerization provides a new approach to stabilizing multiprotein assemblies for analysis of protein mechanisms within their native complexes.

\section{MATERIALS AND METHODS}

Vesicle Preparation. DOPC (1,2-dioleoyl-sn-glycero-3phosphocholine) and the nickel-chelating lipid DOGS-NTA$\mathrm{Ni}^{2+}$ (1,2-dioleoyl-sn-glycero-3-\{[N-(5-amino-1-carboxypentyl)iminodiacetic acid]succinyl $\}$ ) (Avanti Polar Lipids) were combined in chloroform at a 1.5:1 DOPC:DOGS-NTA-Ni ${ }^{2+}$ molar ratio. Lipids were dried into a thin film with a stream of $\mathrm{N}_{2}$ gas and left under a vacuum for $1 \mathrm{~h}$ before being rehydrated with $1 \times \mathrm{PKB}$ \{phosphate kinase buffer $\left[50 \mathrm{mM} \mathrm{K}_{x} \mathrm{H}_{x} \mathrm{PO}_{4}(\mathrm{pH}\right.$ 7.5), $50 \mathrm{mM} \mathrm{KCl}$, and $5 \mathrm{mM} \mathrm{MgCl} 2]$ \} and vortexed extensively (30 s vortex, $5 \mathrm{~min}$ rest, repeated three times) to form multilamellar vesicles, followed by five cycles of $3 \mathrm{~min}$ freezing/ thawing. Freeze/thaw cycles were accomplished by dipping the lipids in liquid nitrogen for $20 \mathrm{~s}$ to freeze and left on the bench for $3 \mathrm{~min}$ and then held for $3 \mathrm{~min}$ in a $37{ }^{\circ} \mathrm{C}$ water bath. Extrusion was then performed with an extrusion apparatus (Avanti Polar Lipids) using a $100 \mathrm{~nm}$ diameter pore size polycarbonate membrane. High-concentration stocks at $3 \mathrm{mM}$ total lipid (1.8 mM DOPC and 1.2 mM DOGS-NTA-Ni ${ }^{2+}$ ) were prepared, and a final [lipid $]_{\text {total }}$ of $725 \mu \mathrm{M}$ was used for assembly (see below). The lipid concentrations were optimized in parallel with CheA and CheW concentrations to maximize kinase activity under conditions under which the available vesicle surface area could accommodate all CF as hexagonal arrays.

Plasmid Construction. The pHTCF4Q plasmid encoding the cytoplasmic fragment (CF) of the aspartate chemoreceptor with glutamine at all four primary methylation sites (4Q) was isolated from $\mathrm{DH} 5 \alpha \mathrm{F}^{\prime}$ E. coli cells. ${ }^{20}$ A TEV-protease (tobacco etch virus) recognition and cleavage sequence (ENLYFQG) was inserted directly following the $\mathrm{N}$-terminal $\mathrm{His}_{6}$-tag of pHTCF4Q using site-directed mutagenesis and polymerase chain reaction (PCR). Forward (5'-GAAAACCTGTATTTTCAGGGCGGATCCCCTATGCAACG-3') and reverse (5'GCCCTGAAAATACAGGTTTTCGTGATGGTGATGGTGATG-3') overlapping primers were designed to include the TEV-protease recognition sequence and were purchased from Eurofins Genomics. The PCR was performed in a thermocycler (Bio-Rad MJ Mini), and reagents, including Phusion DNA polymerase, dNTPs, and DpnI, were purchased from New England Biolabs. The PCR product (pTEVCF4Q, amp ${ }^{\mathrm{R}}$ ) was subjected to DpnI digestion and transformed into $\mathrm{DH} 5 \alpha \mathrm{F}^{\prime}$ for plasmid purification. Following sequence verification (Genewiz), pTEVCF4Q was co-transformed with pCF430 (encoding lacI $^{\mathrm{q}}$ and tet ${ }^{\mathrm{R}}$ ) into BL21(DE3) for protein expression.

Protein Purification. BL21(DE3) E. coli cells expressing $\mathrm{H}_{6} \mathrm{CF}\left(\mathrm{pHTCF} 4 \mathrm{Q}, \mathrm{amp}^{\mathrm{R}}\right.$ ) or $\mathrm{H}_{6}$ TEV-CF (pTEVCF4Q amp ${ }^{\mathrm{R}}$ ) co-transformed with pCF430 (tet ${ }^{\mathrm{R}}$ ) were grown in LuriaBertani (LB) broth with ampicillin $(100 \mu \mathrm{g} / \mathrm{mL})$ and tetracycline $(10 \mu \mathrm{g} / \mathrm{mL})$ at $37{ }^{\circ} \mathrm{C}$ until the optical density at $600 \mathrm{~nm}$ reached approximately 0.6. The temperature was decreased to $15{ }^{\circ} \mathrm{C}$ for induction with $1 \mathrm{mM}$ IPTG for 16-18 h. Cells were pelleted, resuspended in lysis buffer $[75 \mathrm{mM}$ $\mathrm{K}_{x} \mathrm{H}_{x} \mathrm{PO}_{4}(\mathrm{pH} 7.5$ ), $500 \mathrm{mM} \mathrm{NaCl}, 5 \mathrm{mM}$ imidazole, and 1 $\mathrm{mM}$ EDTA], and lysed with a microfluidizer at $16 \mathrm{~K}$ psi. PMSF (1 $\mathrm{mM})$ was added every hour following cell lysis to limit proteolysis. Cell debris was separated by centrifugation and the supernatant applied to a HisTrap FF $\mathrm{Ni}^{2+}$-NTA affinity column (GE Healthcare) equilibrated with 10 column volumes of 75 $\mathrm{mM} \mathrm{K}_{x} \mathrm{H}_{x} \mathrm{PO}_{4}(\mathrm{pH} 7.5), 500 \mathrm{mM} \mathrm{NaCl}$, and $5 \mathrm{mM}$ imidazole. The column was washed with 5 column volumes of $75 \mathrm{mM}$ $\mathrm{K}_{x} \mathrm{H}_{x} \mathrm{PO}_{4}(\mathrm{pH} 7.5), 500 \mathrm{mM} \mathrm{NaCl}$, and $50 \mathrm{mM}$ imidazole, before elution with $75 \mathrm{mM} \mathrm{K}_{x} \mathrm{H}_{x} \mathrm{PO}_{4}(\mathrm{pH} 7.5), 500 \mathrm{mM} \mathrm{NaCl}$, and $500 \mathrm{mM}$ imidazole. Eluted protein was verified by SDSPAGE, and fractions were pooled prior to treatment with $5 \mathrm{mM}$ EDTA to chelate any $\mathrm{Ni}^{2+}$ stripped from the column and dialysis against $75 \mathrm{mM} \mathrm{K} \mathrm{H}_{x} \mathrm{PO}_{4}(\mathrm{pH} 7.5)$ and $75 \mathrm{mM} \mathrm{KCl}$ with $7 \mathrm{kDa}$ molecular weight cutoff SnakeSkin tubing (Thermo Scientific) to remove EDTA and imidazole and lower the $\mathrm{NaCl}$ concentration. Half of the purified $\mathrm{H}_{6}$ TEV-CF was subjected to His-tag removal by TEV-protease cleavage (details below).

Plasmids encoding TEV-cleavable His-tagged CheA ( $p$ TEVcheA, $\left.\operatorname{kan}^{\mathrm{R}}\right)$, CheW $\left(\mathrm{pTEV}\right.$ cheW, $\left.\mathrm{kan}^{\mathrm{R}}\right)$, and CheY (pTEVcheY, $\operatorname{kan}^{\mathrm{R}}$ ) (plasmid construction details described elsewhere $)^{21}$ were expressed in BL21(DE3) and grown at $37{ }^{\circ} \mathrm{C}$ in $\mathrm{LB}$ broth supplemented with $50 \mu \mathrm{g} / \mathrm{mL}$ kanamycin. At an optical density at $600 \mathrm{~nm}$ of $\sim 0.7-0.9,1 \mathrm{mM}$ IPTG was added to induce expression for $3 \mathrm{~h}$ before the cells were harvested and purified with HisTrap affinity chromatography as described for CF above. A different buffer system for CheA, CheW, and CheY purification was used: lysis buffer $[75 \mathrm{mM}$ Tris- $\mathrm{HCl}(\mathrm{pH}$ 7.4), $100 \mathrm{mM} \mathrm{KCl}$, and $1 \mathrm{mM}$ EDTA], equilibration buffer [75 $\mathrm{mM}$ Tris- $\mathrm{HCl}(\mathrm{pH} \mathrm{7.4)}$ and $100 \mathrm{mM} \mathrm{KCl}]$, wash buffer [75 $\mathrm{mM}$ Tris- $\mathrm{HCl}$ ( $\mathrm{pH} 7.4), 100 \mathrm{mM} \mathrm{KCl}$, and $10 \mathrm{mM}$ imidazole], and elution buffer [75 mM Tris- $\mathrm{HCl}(\mathrm{pH} 7.4), 100 \mathrm{mM} \mathrm{KCl}$, and $250 \mathrm{mM}$ imidazole]. Following elution, fractions containing protein were verified by SDS-PAGE, pooled and treated with $5 \mathrm{mM}$ EDTA, and then dialyzed as for CF into 75 $\mathrm{mM}$ Tris- $\mathrm{HCl}$ ( $\mathrm{pH} 7.4$ ) and $100 \mathrm{mM} \mathrm{KCl}$ prior to His-tag removal.

Plasmid pRK793 $\left(\mathrm{amp}^{\mathrm{R}}\right)$ encoding N-terminally His-tagged TEV-protease (a gift from D. Waugh, Addgene plasmid 8827) ${ }^{22}$ 
was expressed in BL21(DE3)-RIL $\left(a m p^{\mathrm{R}}\right)$. Cells were grown at $37^{\circ} \mathrm{C}$ in $\mathrm{LB}$ broth containing $150 \mu \mathrm{g} / \mathrm{mL}$ ampicillin and $50 \mu \mathrm{g} /$ $\mathrm{mL}$ chloramphenicol. Protein production was induced at $30^{\circ} \mathrm{C}$ with $1 \mathrm{mM}$ IPTG for $4 \mathrm{~h}$ when an optical density of 0.6 was reached. The protein purification protocol and buffer system for CheA, CheW, and CheY was also used here (see above).

His-Tag Cleavage with TEV-Protease. Following purification, CheA, CheW, CheW, and $\mathrm{H}_{6}$ TEV-CF were incubated with TEV-protease (purification details given above) at a 50:1 His-tagged protein:TEV-protease molar ratio, and the mixture was shaken at $4{ }^{\circ} \mathrm{C}$ overnight and $25{ }^{\circ} \mathrm{C}$ for $3 \mathrm{~h}$. Complete cleavage was confirmed by a gel shift observed by SDS-PAGE. Cleaved proteins were separated from TEV-protease by being passed through the equilibrated HisTrap column, collected, and concentrated with $10 \mathrm{kDa}$ centrifugal concentrators (Amicon); protein concentrations were measured by the BCA assay (Thermo Scientific), and proteins were frozen in liquid nitrogen and stored at $-80{ }^{\circ} \mathrm{C}$.

Complex Assembly. Preparation of ternary complexes was performed as previously described for vesicles ${ }^{15}$ and $\mathrm{PEG}^{17}$ with some modifications. Briefly, vesicle samples were prepared by combining the following (in order): autoclaved water, $1 \mathrm{mM}$ PMSF dissolved in $100 \%$ ethanol, phosphate kinase buffer (PKB) from a $5 \times$ stock (the $1 \times$ stock being $50 \mathrm{mM} \mathrm{K}_{x} \mathrm{H}_{x} \mathrm{PO}_{4}$, $50 \mathrm{mM} \mathrm{KCl}$, and $5 \mathrm{mM} \mathrm{MgCl}$ ), $12 \mu \mathrm{M}$ CheA, $24 \mu \mathrm{M}$ CheW, $30 \mu \mathrm{M} \mathrm{CF}\left(\mathrm{H}_{6} \mathrm{CF}, \mathrm{H}_{6} \mathrm{TEV}-\mathrm{CF}\right.$, or $\left.\Delta \mathrm{H}_{6} \mathrm{CF}\right)$, and $725 \mu \mathrm{M}$ vesicles (prepared as described above). PEG-assembled samples were made by combining the following (in order): autoclaved water, $1 \mathrm{mM}$ PMSF, PKB, $12 \mu \mathrm{M}$ CheA, $20 \mu \mathrm{M}$ CheW, $50 \mu \mathrm{M}$ CF $\left(\mathrm{H}_{6} \mathrm{CF}, \mathrm{H}_{6} \mathrm{TEV}-\mathrm{CF}\right.$, or $\left.\Delta \mathrm{H}_{6} \mathrm{CF}\right), 7.5 \%(\mathrm{w} / \mathrm{v})$ PEG8000 [from a $40 \%(\mathrm{w} / \mathrm{v})$ stock], and $4 \%(\mathrm{w} / \mathrm{v})$ D-trehalose [from a $40 \%(\mathrm{w} / \mathrm{v})$ stock]. Metal-assembled samples were prepared under protein and buffer conditions identical to those optimized for vesicle assembly, except that vesicles were replaced with metal salts $\left(\mathrm{NiCl}_{2} \cdot 6 \mathrm{H}_{2} \mathrm{O}, \mathrm{ZnCl}_{2}\right.$ anhydrous, $\mathrm{CuCl}_{2} \cdot 2 \mathrm{H}_{2} \mathrm{O}, \mathrm{MnCl}_{2} \cdot 4 \mathrm{H}_{2} \mathrm{O}$, and $\mathrm{CoCl}_{2} \cdot 6 \mathrm{H}_{2} \mathrm{O}$, all obtained from Sigma-Aldrich) prepared at $\sim 1 \mathrm{mM}$ in autoclaved Milli-Q $\mathrm{H}_{2} \mathrm{O}$. Metal stock concentrations were verified before being used (see below).

Once combined, samples were incubated in a $25{ }^{\circ} \mathrm{C}$ water bath for $4 \mathrm{~h}$ or overnight before use. To measure kinetics of assembly, both activity and sedimentation (below) were measured at time points immediately following addition of all complex components.

Activity and Binding Assays. Kinase activity was measured using an enzyme-coupled ATPase assay that couples $\mathrm{NADH}$ oxidation to consumption of ATP. ${ }^{15,23,24}$ Briefly, activity measurements were conducted immediately following a 100-fold dilution of assembled complexes into PKB containing $55 \mu \mathrm{M}$ CheY, $2.2 \mathrm{mM}$ phosphoenolpyruvate, 4 $\mathrm{mM}$ ATP, $250 \mu \mathrm{M} \mathrm{NADH}$, and 20 units of PK/LDH enzyme (Sigma-Aldrich). The background activity of $\mathrm{CheY}$ under identical conditions in the absence of the complex was subtracted before calculation of kinase activity. The kinase activity (inverse seconds) was determined from the linear change in absorbance at $340 \mathrm{~nm}\left[\mathrm{~d}[\mathrm{ATP}] / \mathrm{d} t=-6220\left(\mathrm{~d}_{340} /\right.\right.$ $\mathrm{d} t)]$ over $1.5 \mathrm{~min}$. Total activity is based on the full amount of CheA in the sample $(12 \mu \mathrm{M})$, while the specific activity considers only the amount of CheA in the complex, based on quantification from the sedimentation assay (below).

The amount of bound protein was determined with a sedimentation assay performed at $25{ }^{\circ} \mathrm{C}$ in a benchtop ultracentrifuge (Beckman TLX, TLA 120.2 rotor, 125000g, 30 $\min$ ). Typically, a $35 \mu \mathrm{L}$ aliquot of sample (in either assembled ternary complexes or individual proteins) was centrifuged. Following sedimentation, the supernatant was carefully removed and placed into a clean Eppendorf tube to minimize contamination of free protein in the pellet containing the bound fraction of proteins. The pellets were slowly resuspended to the original volume in autoclaved Milli-Q $\mathrm{H}_{2} \mathrm{O}$ and vortexed to homogenize the resuspension. Aliquots of Total (free plus bound protein, before sedimentation), Supernatant (free protein), and Pellet (bound protein) were subjected to SDS-PAGE (12.5\% acrylamide) and stained with Gel-code Blue (Pierce Chemical Co.). Gels were imaged by densitometry with a Gel Doc EZ Imager (Bio-Rad), and the integrated intensities were analyzed with ImageJ. ${ }^{25}$ The bound concentrations were computed as $\left(I_{\text {pellet }} / I_{\text {total }}\right)$ [protein $]_{\text {total }}$ for each protein to be quantified. For excess CheA and CheW conditions used in this study, quantification of bound protein by the pellet was more reproducible than $I_{\text {total }}-I_{\text {supernatant }}$. Gels included two additional lanes of the Total sample diluted 6- and 12-fold such that a calibration curve from three intensities for known concentrations could be calculated. The $y$-intercept was then subtracted from each integrated intensity to correct for the gel background intensity and more accurately estimate the fraction of protein bound in a complex.

Determination of Metal Concentration. Metal concentrations of the $\sim 1 \mathrm{mM}$ aqueous metal stocks $\left(\mathrm{NiCl}_{2}, \mathrm{ZnCl}_{2}\right.$, $\mathrm{CuCl}_{2}, \mathrm{MnCl}_{2}$, and $\mathrm{CoCl}_{2}$ ) and the amounts of metal bound to $\mathrm{H}_{6} \mathrm{CF}$ (alone or in complex) were measured using a PerkinElmer Optima DV4300 inductively coupled plasma optical emission spectroscopy (ICP-OES) instrument. Metal standards (TraceCERT by Sigma-Aldrich) were used to produce a calibration curve for each metal at 0.1, 0.2, 0.75, 1, 2 , and $10 \mathrm{ppm}$. Metal stocks were diluted 100-fold, and protein/metal samples were diluted 10-fold into Milli-Q water that was also used to blank the instrument. Protein samples were prepared by overnight incubation of $30 \mu \mathrm{M} \mathrm{H}_{6} \mathrm{CF}$ (alone or with $12 \mu \mathrm{M}$ CheA and $24 \mu \mathrm{M}$ CheW) with the metals that produced active complexes at optimal concentrations $(180 \mu \mathrm{M}$ $\mathrm{NiCl}_{2}, 300 \mu \mathrm{M} \mathrm{ZnCl}$, or $360 \mu \mathrm{M} \mathrm{CoCl}_{2}$ ) in a $25{ }^{\circ} \mathrm{C}$ water bath. Aliquots of these samples were then subjected to ultracentrifugation $\left(60 \mathrm{~K} \mathrm{rpm}\right.$ for $30 \mathrm{~min}$ at $25^{\circ} \mathrm{C}$ ) to separate large metal-protein complexes from unbound protein and metal in the supernatant. Bound protein and metals in the pellet were carefully resuspended to the initial volume in Milli$\mathrm{Q}$ water. The entire resuspended pellet was used for ICP-OES analysis, so that any chunks of protein pellet were still part of the sample that was measured.

SEC-MALS. Size exclusion chromatography and multi-angle light scattering (SEC-MALS) were used to monitor metalmediated complex formation. The SEC instrument is coupled to an 18-angle static light scattering detector (DAWN HELEOS-II), a dynamic light scattering detector (WyattQELS), and a differential refractometer (Optilab T-rEX, Wyatt Technology). Proteins were injected onto a TSKgel G2000SW $_{\mathrm{XL}}$ column maintained at $4{ }^{\circ} \mathrm{C}$ and pre-equilibrated overnight with $\mathrm{PKB}$ buffer $(\mathrm{pH} 7.0)$ kept on ice. Typical injections were $75 \mu \mathrm{L}$ of $0.5-3 \mathrm{mg} / \mathrm{mL}$ protein. Data were collected every second for $30 \mathrm{~min}$ at a flow rate of $0.5 \mathrm{~mL} / \mathrm{min}$. Protein elution was monitored at $A_{280}$ and $A_{214}$, in addition to static and dynamic light scattering. The accompanying ASTRA VI software was used to determine molar mass, peak polydispersity, and ultraviolet (UV) peak areas for all individual 
peaks and the entire elution to determine the percent loss in a precolumn $0.22 \mu \mathrm{m}$ filter.

Electron Cryo-Tomography (ECT). Samples were prepared by mixing protein assemblies (as above) with a bovine serum albumin-treated $10 \mathrm{~nm}$ colloidal gold solution (Cell Microscopy Core, Utrecht University, Utrecht, The Netherlands). After being briefly vortexed, $3 \mu \mathrm{L}$ mixtures were applied to freshly plasma-cleaned R2/2 copper Quantifoil grids (Quantifoil Micro Tools). Blotting and plunge freezing in ethane were performed for approximately $1 \mathrm{~s}$ with a Leica EMGP instrument (Leica microsystems, Wetzlar, Germany), set at $20{ }^{\circ} \mathrm{C}$ and $95 \%$ humidity. Grids were stored in liquid nitrogen until they were imaged. Data were collected on a Titan Krios transmission electron microscope from Thermo Fisher Scientific (formerly FEI; Hillsboro, OR) with a field emission gun operating at $300 \mathrm{kV}$. The microscope was equipped with a Gatan (Pleasanton, CA) image filter and a Gatan K2 Summit direct electron detector. Data were acquired using Tomography version 4.0 (Thermo Fisher Scientific) in batch mode. Tilt series for PEG and $\mathrm{Ni}(\mathrm{II})$-assembled $\mathrm{H}_{6} \mathrm{CF}$ ternary complexes were collected at nominal magnifications of $42000 \times$ and $33000 \times$, respectively. A discontinuous tilt scheme was used for imaging, taking images from $0^{\circ}$ to $-60^{\circ}$ followed by $0^{\circ}$ to $60^{\circ}$ with a $2^{\circ}$ tilting increment. The cumulative dosage for each tilt series was $80 \mathrm{e} / \mathrm{A}^{2}$. Defocus was set to $-8 \mu \mathrm{m}$. The tilt series for $\mathrm{Ni}\left(\mathrm{II}\right.$ )-assembled $\mathrm{H}_{6} \mathrm{CF}$ (without CheA or $\mathrm{CheW}$ ) and PEG-assembled $\Delta \mathrm{H}_{6} \mathrm{CF}$ complexes were collected using the same tilt scheme but at a defocus of $-300 \mathrm{~nm}$ with a volta phase plate (VPP) (Thermo Fisher Scientific). The VPP was heated to $225{ }^{\circ} \mathrm{C}$ and activated for $80 \mathrm{~s}$ before each tilt series aiming to generate an approximate phase shift of $90^{\circ} .^{26}$ An extra $5 \mathrm{~s}$ of conditioning time was applied between each tilt image. All images were acquired using the low-dose routine integrated in the Tomography software. Drift correction and tilt series alignment were performed with software package IMOD. ${ }^{27,28}$ Tomograms were reconstructed using both weighted back-projection (WBP) and nine iterations of simultaneous iterative reconstruction (SIRT). PEET was used for subvolume averaging. ${ }^{29}$ Visualization and image analysis were performed with ImageJ and Chimera. ${ }^{25,30}$

\section{RESULTS}

Divalent Metals Restore Chemoreceptor Ternary Complex Formation and Function. Under conditions similar to those used to form functional complexes of aspartate receptor $\mathrm{CF}$, CheA, and $\mathrm{CheW}$ with templating vesicles, we have discovered that some divalent metals are sufficient to restore function, with no requirement for vesicles. A series of metal titrations reveal the conditions needed to restore both kinase activity of CheA (measured with an enzyme-coupled ATPase assay, using the native phosphoryl acceptor protein CheY) and ternary complex formation (measured with sedimentation assays). Five divalent metal chlorides were tested $\left(\mathrm{NiCl}_{2}, \mathrm{ZnCl}_{2}, \mathrm{CoCl}_{2}, \mathrm{CuCl}_{2}\right.$, and $\left.\mathrm{MnCl}_{2}\right)$ at concentrations ranging from 0 to $540 \mu \mathrm{M}$ while protein concentrations were kept constant at levels that promote maximal incorporation of CF into functional complexes [30 $\mu \mathrm{M}$ CF with excess CheA $(12 \mu \mathrm{M})$ and CheW $(24 \mu \mathrm{M})]$. As shown in Figure 1, $\mathrm{NiCl}_{2}$ promotes active complex formation at the lowest concentrations, with maximum kinase activity reached at $180 \mu \mathrm{M} \mathrm{NiCl}_{2}$. The optimal $\mathrm{ZnCl}_{2}$ concentration for kinase activity is $300 \mu \mathrm{M}$, and the total kinase activity is $90 \%$ of the highest observed for $\mathrm{NiCl}_{2}$. While $\mathrm{CoCl}_{2}$ also produced active

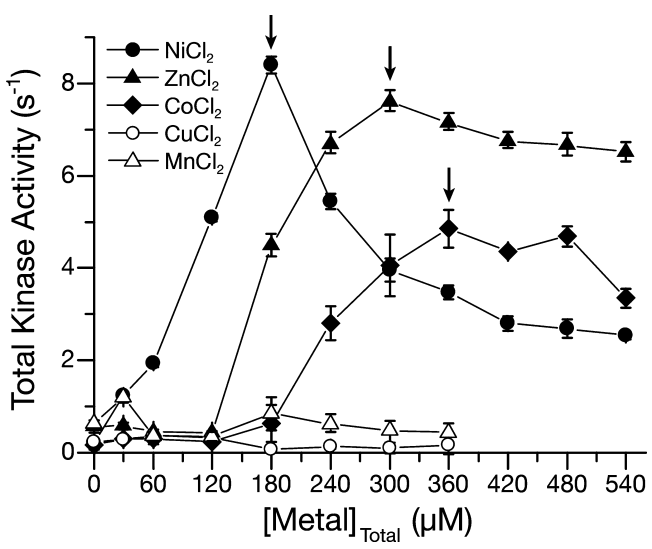

Figure 1. Three divalent metals promote kinase activity at different optimal metal concentrations. All experiments use excess CheA and CheW, under conditions optimized for maximal incorporation of $\mathrm{CF}$ into complexes with maximal kinase activity $\left(30 \mu \mathrm{M} \mathrm{H}_{6} \mathrm{CF}, 12 \mu \mathrm{M}\right.$ CheA, and $24 \mu \mathrm{M}$ CheW). Additions of $\mathrm{NiCl}_{2}(\mathbf{O}), \mathrm{ZnCl}_{2}(\mathbf{\Delta})$, or $\mathrm{CoCl}_{2}()_{)}$each promote kinase activity, with $\mathrm{NiCl}_{2}$ promoting the highest activity, followed by $\mathrm{ZnCl}_{2}$ and then $\mathrm{CoCl}_{2} \cdot \mathrm{CuCl}_{2}(\mathrm{O})$ and $\mathrm{MnCl}_{2}(\triangle)$ do not promote activity: activity comparable to that of the no-metal control is observed at all metal concentrations. As a positive control, PEG-mediated samples were run in parallel, with typical total kinase activities of $\sim 11 \mathrm{~s}^{-1}$. Comparisons of specific kinase activity (per bound CheA) among PEG-, vesicle-, and $\mathrm{NiCl}_{2}$-mediated assemblies are plotted in Figure 2B. Arrows denote maximally active conditions used for further studies, including metal:protein stoichiometry measurements listed in Table 1. Activities are averages of four to eight replicates measured on two or three days; error bars indicate tone standard deviation. For this plot, measurements on each day were averaged, and the averages for all days were then combined, with propagation of the errors.

complexes in this titration series, the highest kinase activity (reached at $360 \mu \mathrm{M} \mathrm{CoCl}_{2}$ ) is only $50 \%$ of that of the optimal $\mathrm{NiCl}_{2}$ sample. Thus, the relative efficiencies of these metals for promoting assembly of functional complexes decrease as follows: $\mathrm{NiCl}_{2}>\mathrm{ZnCl}_{2}>\mathrm{CoCl}_{2}$. Interestingly, the sedimentation trends for $\mathrm{CF}$, CheA, and $\mathrm{CheW}$ with each metal titration track mostly with the respective onset of activity (Figure $\mathrm{S} 1$ ). For example, $\mathrm{NiCl}_{2}$-assembled complexes show both activity and sedimentation beginning at low $\mathrm{NiCl}_{2}$ concentrations, and $\mathrm{ZnCl}_{2}$-assembled complexes show nearly zero sedimentation until $180 \mu \mathrm{M} \mathrm{ZnCl}_{2}$, where activity is first observed. Furthermore, maximal sedimentation of $\mathrm{CF}$, CheA, and $\mathrm{CheW}$ is reached for most cases under conditions that give maximal activity, and the $\mathrm{CoCl}_{2}$ titration reaches activity and sedimentation of only $50 \%$ of those of the optimal $\mathrm{NiCl}_{2}$ sample. Thus, three divalent metals restore the ability of the chemotaxis receptor $\mathrm{CF}$ to assemble with CheA and CheW into sedimentable complexes that activate the kinase CheA.

Interestingly, $\mathrm{NiCl}_{2}$ concentrations of $>180 \mu \mathrm{M}$ are clearly detrimental to kinase activity, and sedimentation of $\mathrm{CF}$ increases an additional 15\%; CheA and $\mathrm{CheW}$ sedimentations remain constant (Figure S1). In contrast, $\mathrm{ZnCl}_{2}$ and $\mathrm{CoCl}_{2}$ cause an only modest decrease in activity at high concentrations (and no significant additional sedimentation).

Neither $\mathrm{CuCl}_{2}$ nor $\mathrm{MnCl}_{2}$ restored formation of active complexes. Kinase activity throughout the titration is similar to that of the proteins with no metal $\left(<1 \mathrm{~s}^{-1}\right)$. Furthermore, all samples with $\mathrm{CuCl}_{2}$ and $\mathrm{MnCl}_{2}$ also had very low protein sedimentation values of $<15 \%$, again similar to levels for the nometal control, with the exception of $\mathrm{CuCl}_{2}$ and $\mathrm{CheA}$. At high 
$\mathrm{CuCl}_{2}$ concentrations, nearly all of CheA sedimented (data not shown). Because there is no appreciable kinase activity or sedimentation of $\mathrm{CheW}$ and $\mathrm{H}_{6} \mathrm{CF}$, we can conclude that $\mathrm{CuCl}_{2}$ is most likely causing aggregation of CheA.

Measurements of bound metals indicate that the active complexes have metal:protein stoichiometries close to $1: 1$ $[\mathrm{Ni}(\mathrm{II})$ and $\mathrm{Co}(\mathrm{II})]$ and $3: 1 \quad[\mathrm{Zn}(\mathrm{II})]$. The metal ion concentrations bound to CF were determined using inductively coupled plasma optimal emission spectroscopy (ICP-OES), in samples of active complexes (prepared with CheA and CheW) as well as CF alone. Metals producing active complexes lead to sedimentation of both $\mathrm{CF}$ alone and $\mathrm{CF}$ with CheA and CheW (with the exception of $\mathrm{CoCl}_{2}+\mathrm{CF}$ alone, which does not sediment). Samples were prepared with each metal at the optimal concentration based on the activity data (Figure 1, arrows) and incubated for long assembly times that maximize kinase activity $(>4 \mathrm{~h})$. The bound protein ( $\mathrm{CF}$ alone or in complex with CheA and $\mathrm{CheW}$ ) and metal were separated from free protein and metal by ultracentrifugation. Resuspended pellets were then analyzed for metal content by ICP-OES and protein content by SDS-PAGE (via comparison to a $\mathrm{CF}$ standard measured by the BCA assay). Unfortunately, we were unable to implement sulfur quantification by ICP-OES, which would have enabled measurement of a more accurate metal:protein ratio as the number of sulfur atoms per $\mathrm{CF}$ is known. As listed in Table 1, CF alone and CF in complex have

Table 1. Stoichiometries of Metal Binding to CF Measured by ICP-OES ${ }^{a}$

\begin{tabular}{|c|c|c|}
\hline metal added $^{b}$ & metal bound to CF alone ${ }^{c}$ & metal bound to CF in complex ${ }^{d}$ \\
\hline $\mathrm{Ni}(\mathrm{II})$ & $1.2 \pm 0.04$ & $1.1 \pm 0.05$ \\
\hline $\mathrm{Zn}(\mathrm{II})$ & $3.8 \pm 0.16$ & $3.1 \pm 0.12$ \\
\hline $\mathrm{Co}(\mathrm{II})$ & $\mathrm{ND}^{e}$ & $1.1 \pm 0.15$ \\
\hline
\end{tabular}

${ }^{a}$ Data are averages \pm one standard deviation for the number of metal ions bound per CF monomer from 10 independent ICP-OES measurements of each metal. ${ }^{b}$ Metal added at concentrations found to give maximally active complexes (Figure 1, arrows). ${ }^{c}$ Samples contain $30 \mu \mathrm{M} \mathrm{CF} .{ }^{d}$ Samples contain $30 \mu \mathrm{M} \mathrm{CF}, 12 \mu \mathrm{M}$ CheA, and 24 $\mu \mathrm{M}$ CheW. ${ }^{e} \mathrm{CoCl}_{2}$ with $\mathrm{CF}$ alone does not sediment, and thus, metal content could not be measured.

nearly identical stoichiometries for $\mathrm{Ni}$ (II) and $\mathrm{Co}(\mathrm{II})$, which suggests that metals bind similarly to $\mathrm{CF}$ in both cases. Moreover, the calculated stoichiometries are both close to one metal ion per CF monomer. In contrast, $\mathrm{Zn}$ (II) exhibited both a higher and a more variable stoichiometry of $3.8 \mathrm{Zn}$ (II) per $\mathrm{CF}$ alone and 3.1 per CF in complexes. Thus, for all three metals, we can conclude that a large excess (6-12 equiv) is necessary to drive assembly to maximally active CF ternary complexes, but only a fraction of metal is directly involved in the assembly. All further studies were performed on $\mathrm{Ni}(\mathrm{II})$-assembled samples at $180 \mu \mathrm{M} \mathrm{NiCl}_{2}$.

The Receptor His-Tag Is Essential for Metal-Mediated Assembly. We hypothesized that the His-tag could be involved in the metal-mediated assembly of functional chemoreceptor complexes, perhaps via stabilization of $\mathrm{CF}$ dimers or oligomers. To test this, we engineered a variant of the $\mathrm{CF}$ construct (henceforth called $\mathrm{H}_{6} \mathrm{CF}$ for the sake of clarity) by inserting the recognition and cleavage sequence for TEVprotease after the His-tag $\left(\mathrm{H}_{6} \mathrm{TEV}-\mathrm{CF}\right)$. TEV-protease cleavage of $\mathrm{H}_{6}$ TEV-CF yields $\Delta \mathrm{H}_{6} \mathrm{CF}$, with the native $\mathrm{CF}$ sequence plus a single glycine at the $\mathrm{N}$-terminus. For each version of $\mathrm{CF}$
$\left(\mathrm{H}_{6} \mathrm{CF}\right.$ and $\mathrm{H}_{6}$ TEV-CF with His-tags and $\Delta \mathrm{H}_{6} \mathrm{CF}$ with no Histag, as shown in Figure 2A), we tested the assembly of ternary complexes with CheA and CheW by three in vitro methods [vesicles, PEG, and $\mathrm{Ni}(\mathrm{II})$ ] and measured both the kinase activity and protein stoichiometry of sedimented complexes.

The three proteins together in buffer with no vesicles, PEG, or divalent metal show low kinase activity (Figure 2B, None) and $<15 \%$ binding (not shown). We had previously observed variable levels of kinase activity for $\mathrm{H}_{6} \mathrm{CF}$, CheA, and CheW assembled in the absence of vesicles, PEG, or added metals and realized $\mathrm{H}_{6} \mathrm{CF}$ may contain variable amounts of $\mathrm{Ni}$ (II), stripped from the NTA affinity column during purification. ${ }^{31}$ We incorporated a $5 \mathrm{mM}$ EDTA treatment step into all purifications, following elution of protein from the column, and this EDTA is removed in the subsequent dialysis step (see Materials and Methods). Thus, the low level of activity and sedimentation observed in the absence of vesicles, PEG, or metal (Figure 2B, None) is not due to adventitious Ni(II) but presumably reflects the low stability of these complexes formed with the truncated CF.

As shown in Figure $2 \mathrm{~B}$, both $\mathrm{H}_{6} \mathrm{CF}$ and $\mathrm{H}_{6} \mathrm{TEV}-\mathrm{CF}$ complexes are functional with all assembly methods, indicating that the TEV insertion does not interfere with assembly of functional CF complexes. As anticipated, removing the His-tag results in no kinase activity and background levels of protein binding for both vesicle and $\mathrm{Ni}$ (II) assembly methods, demonstrating that the His-tag is required for metal-mediated assembly.

The native stoichiometry of chemoreceptor arrays is thought to be 6:1:2 receptor:CheA:CheW. ${ }^{9,10}$ As shown in Figure 2C, all active complexes of the different constructs assembled with vesicles, PEG, or Ni(II) display near-native stoichiometries. The variation in CheW (ranging from 2.1 to 3.0) may be due to weak staining of $\mathrm{CheW}$, resulting in less accurate quantification. Overall, the stoichiometries are consistent with the nativelike architecture of PEG arrays, which have high CheA occupancy observed by electron cryotomography. ${ }^{12}$ Thus, PEG mediates assembly via molecular crowding that does not require the Histag; both vesicle and $\mathrm{Ni}(\mathrm{II})$ assembly require the His-tag to mediate assembly of complexes with comparable kinase activity and protein stoichiometry.

Metal-Mediated Complexes Form Arrays with Nativelike Architecture. Chemoreceptor complexes with CheA and CheW form an extended lattice of hexagonal arrays located within the bacterial inner membrane that is responsible for ensuring a sensitive and integrated response to chemical gradients. Because ternary complex formation and kinase activity have been observed in the absence of arrays, ${ }^{32-34}$ we used electron cryotomography (ECT) to assess the structural features and homogeneity of the metal-mediated complexes. ECT images of $\mathrm{Ni}(\mathrm{II})$-mediated $\mathrm{H}_{6} \mathrm{CF}$ ternary complexes prepared under conditions leading to maximal activity reveal clear high-contrast hexagonal lattices (Figure 3A). With $12 \mathrm{~nm}$ center-to-center spacing between hexagons, these are indistinguishable from in vivo arrays and from our other in vitro assemblies formed with templating vesicles and PEG-mediated crowding. ${ }^{12}$ Furthermore, isosurface averages extracted from the $\mathrm{Ni}(\mathrm{II})$ - and PEG-mediated tomograms are remarkably similar to the electron density from in vivo intact receptors (Figure S2). Interestingly, Ni(II)-mediated arrays also form the sandwichlike structures seen with PEG (Figure 3B). This architecture is likely necessary to stabilize the membrane- 

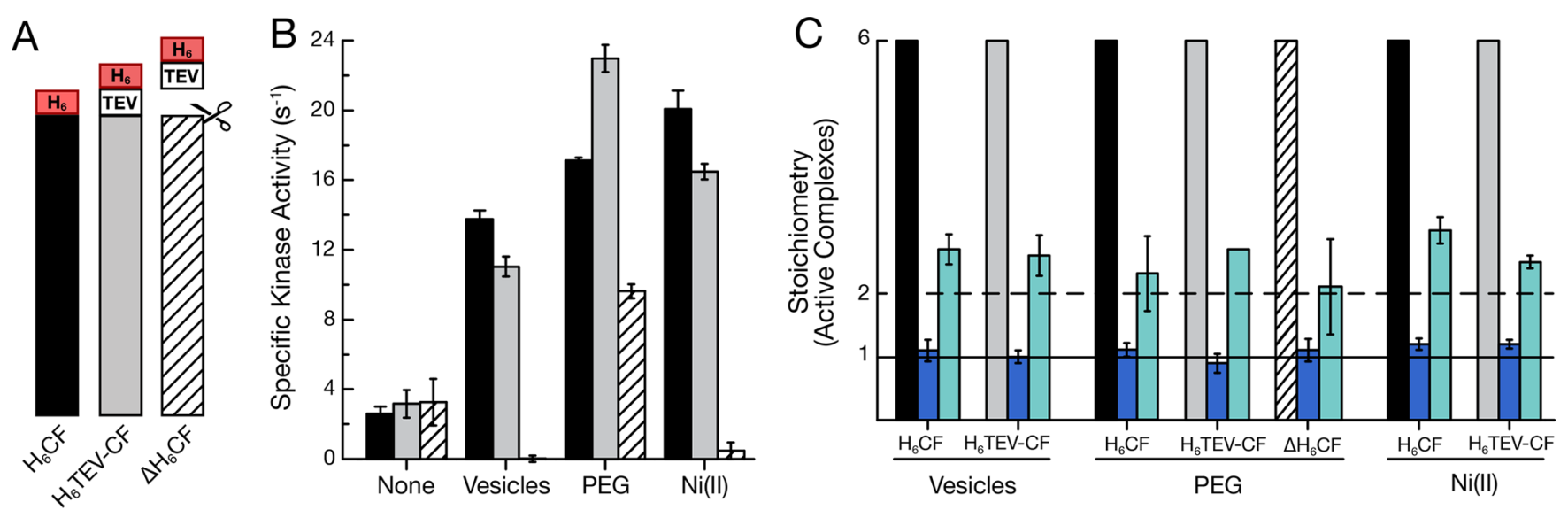

Figure 2. Characterization of in vitro-assembled ternary complexes reveals the receptor His-tag is required for metal-mediated assembly of active complexes with nativelike stoichiometry. (A) Cartoon depicting constructs tested to determine the role of the His-tag $\left(\mathrm{H}_{6}\right.$, red box) in metalmediated assembly of active complexes. (B) Specific activity of CheA kinase assembled with CheW and His-tagged receptor (black for $\mathrm{H}_{6} \mathrm{CF}$ or gray for $\mathrm{H}_{6} \mathrm{TEV}-\mathrm{CF}$ ) or non-His-tagged receptor (striped for $\Delta \mathrm{H}_{6} \mathrm{CF}$ ). Activities are averages of four to eight replicates measured on two to four days; error bars indicate \pm one standard deviation. (C) Stoichiometries for active complexes determined as the ratio of proteins in the sedimented complexes. The $\sim 25-28 \mu \mathrm{M}$ sedimented CF was set to 6 for calculations of the relative amounts of bound CheA (blue) and CheW (cyan), based on ratios of band intensities in SDS-PAGE of sedimented complexes. Horizontal solid and dashed lines correspond to native 6:1:2 molar stoichiometries. Stoichiometries are averages of two to four replicates measured on two to four days; error bars indicate \pm one standard deviation. Error bars are either large or missing for CheW stoichiometries in PEG complexes, because of gel distortions from PEG in the CheW molecular weight range.
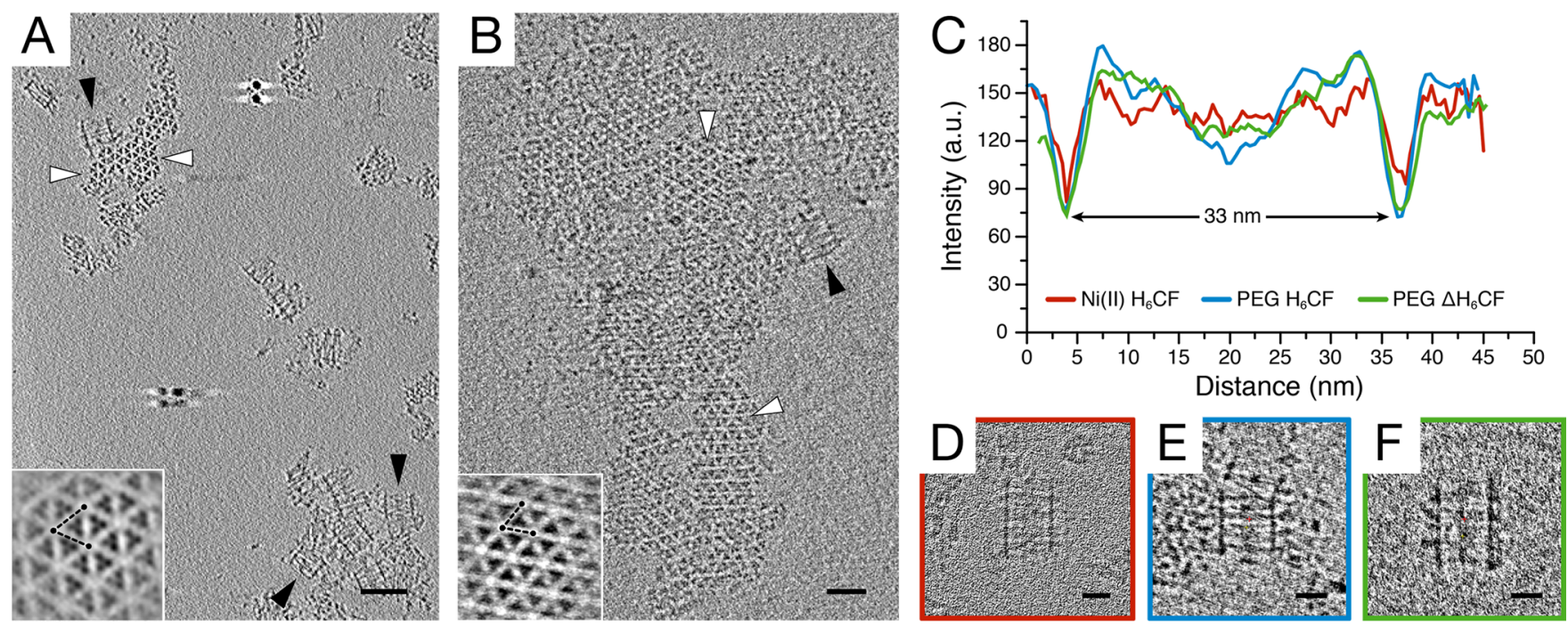

Figure 3. $\mathrm{Ni}$ (II)-mediated functional complexes form arrays with nativelike architecture similar to arrays formed by molecular crowding (PEGmediated arrays). Tomographic slices of (A) Ni(II)-mediated $\mathrm{H}_{6} \mathrm{CF}$ and (B) PEG-mediated $\mathrm{H}_{6} \mathrm{CF}$ show both top-down patches of hexagonal arrays (white arrows) and side view sandwichlike structures (black arrows) made from two layers of CF with overlapping $\mathrm{N}$ - and $\mathrm{C}$-termini that are sandwiched between baseplates of CheA and $\mathrm{CheW}$ on the outside. Scale bars are $50 \mathrm{~nm}$, and insets show enlarged subvolume averages of the hexagonal array with the canonical $12 \mathrm{~nm}$ center-to-center spacing (dotted lines in the insets of panel A and B are $12 \mathrm{~nm}$ ) that is identical to that of in vivo arrays. 8 , 12 (C) Comparison of intensities of the three-dimensional volume reveals that sandwich thicknesses for three sample types are all close to $33 \mathrm{~nm}$. Five separate cubes containing sandwiches of similar proportions were averaged for each sample (Figure S3). (D-F) Example twodimensional tomographic slices of sandwiches from $\mathrm{Ni}(\mathrm{II})$-mediated $\mathrm{H}_{6} \mathrm{CF}$, PEG-mediated $\mathrm{H}_{6} \mathrm{CF}$, and PEG-mediated $\Delta \mathrm{H}_{6} \mathrm{CF}$ ternary complexes used to determine intensity across the sandwich length. Scale bars are $20 \mathrm{~nm}$.

proximal ends of the long CF in the absence of organization by a membrane.

To further investigate the structural similarities between arrays assembled by these methods, we measured the baseplate distances between $\mathrm{CheA} / \mathrm{CheW}$ layers for three assemblies that formed sandwiches. Figure 3C, a plot of the intensity of the three-dimensional volume of the side view for $\mathrm{Ni}(\mathrm{II})$-mediated $\mathrm{H}_{6} \mathrm{CF}$, PEG-mediated $\mathrm{H}_{6} \mathrm{CF}$, and PEG-mediated $\Delta \mathrm{H}_{6} \mathrm{CF}$ sandwiches (examples in Figure $3 \mathrm{D}-\mathrm{F}$ ) reveals identical distances of $33 \mathrm{~nm}$ between baseplates. Given an approximate $\mathrm{H}_{6} \mathrm{CF}$ receptor length of $\sim 21.8 \mathrm{~nm}$ (145 residues, assuming they are all $\alpha$-helical) from the $\mathrm{N}$-terminus to the membranedistal tip, this $33 \mathrm{~nm}$ sandwich thickness predicts that CFs from each side of the sandwich overlap with each other in the central $\sim 10.6 \mathrm{~nm}$ region. This may be consistent with the disorder (low electron density) observed in the approximately central one-third of the sandwich, as seen in a side view of the isosurfaces of the electron density calculated by subvolume 

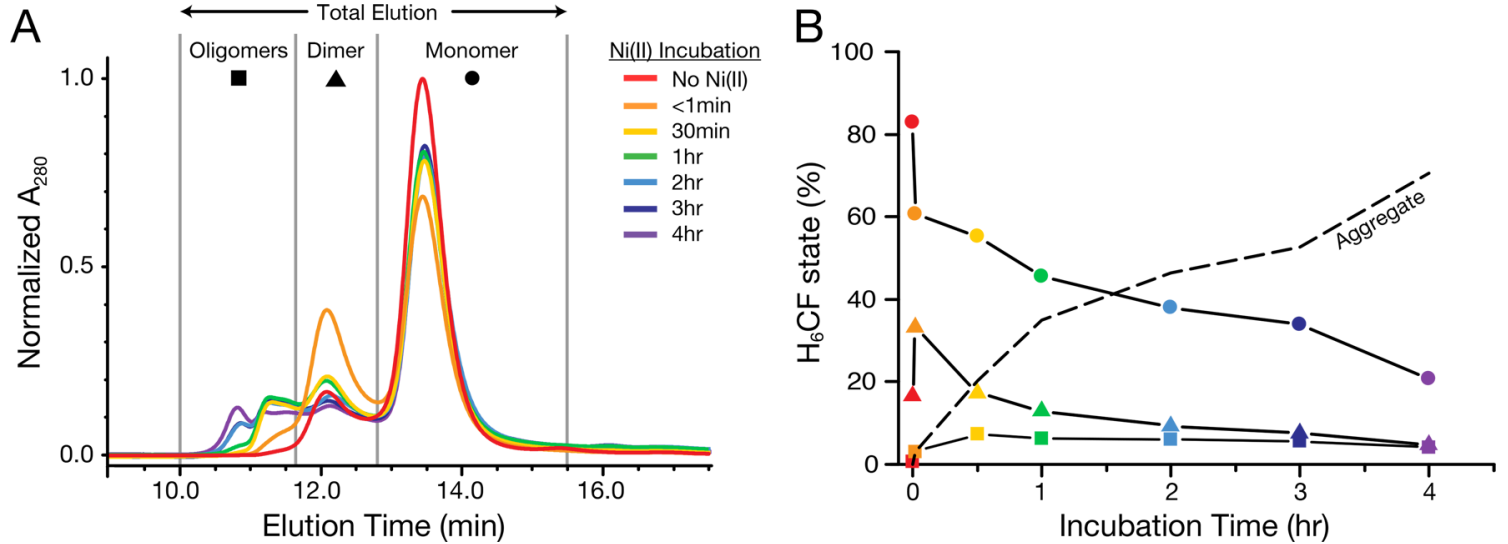

Figure 4. $\mathrm{Ni}(\mathrm{II})$ stabilizes the $\mathrm{H}_{6} \mathrm{CF}$ dimer, which in turn favors larger oligomers. (A) SEC-MALS chromatograms of $30 \mu \mathrm{M} \mathrm{H}_{6} \mathrm{CF}$ incubated with $180 \mu \mathrm{M} \mathrm{NiCl}_{2}$, colored by rainbow according to the increasing incubation time. Vertical lines indicate elution time bounds used to distinguish ther monomer (12.8-15.5 $\mathrm{min})$, dimer (11.7-12.8 $\mathrm{min})$, and oligomers $(10-11.7 \mathrm{~min})$. Although identical volumes $(75 \mu \mathrm{L})$ of the same sample were injected, some $\mathrm{H}_{6} \mathrm{CF}$ aggregate was caught in the precolumn filter. Chromatograms are normalized to a value of 1 for the largest peak in the series. These data are further scaled to the same total area to account for aggregated protein (B, dashed line). (B) The peak areas of the monomer (circle), dimer (triangle), and oligomers (square) were used to calculate the amount of $\mathrm{H}_{6} \mathrm{CF}$ in each state for all incubation times. The percent $\mathrm{H}_{6} \mathrm{CF}$ in aggregates larger than the $0.22 \mu \mathrm{m}$ precolumn filter (dashed line) was calculated from the loss of area under the SEC elution curve.

averaging of tomograms for $\mathrm{Ni}(\mathrm{II})$ - and PEG-mediated $\mathrm{H}_{6} \mathrm{CF}$ (Figure S2). Remarkably, the similarity in baseplate distances indicates that the overlap interactions that stabilize the sandwich assembly do not depend critically on what stabilizes the complexes (metal or PEG) or on the sequence of the $\mathrm{N}$ termini $\left(\mathrm{H}_{6} \mathrm{CF}\right.$ vs $\left.\Delta \mathrm{H}_{6} \mathrm{CF}\right)$ that are present in the overlap region. Finally, the similarity in the architecture of the PEGassembled $\mathrm{H}_{6} \mathrm{CF}$ and $\Delta \mathrm{H}_{6} \mathrm{CF}$ arrays indicates that the ECT resolution is not sufficient to detect whatever differences in structure and dynamics account for the 2 -fold difference in kinase activity (Figure 2B) between these samples.

Insight into Array Assembly and Properties. The results presented above suggest that metal binds to the His-tag of $\mathrm{H}_{6} \mathrm{CF}$ and somehow stabilizes formation of the functional, nativelike array with CheA and CheW. Within the native architecture, what interactions could be stabilized by metal bridging two His-tags? The N-terminal His-tags are adjacent within the $\mathrm{H}_{6} \mathrm{CF}$ dimer. In contrast, His-tags on two different dimers are not adjacent in the trimer of dimers (they are $>65 \AA$ apart in the ECT-derived structural model, Protein Data Bank entry 3JA6), ${ }^{10}$ and His-tags on the two $\mathrm{H}_{6} \mathrm{CF}$ layers are not likely to be adjacent in the sandwich (they are on opposite sides of the $\sim 10 \mathrm{~nm}$ overlap region). Thus, it seems likely that metal binding bridges two His-tags within a $\mathrm{H}_{6} \mathrm{CF}$ dimer, and stabilization of the dimer drives assembly of the functional array. To investigate this, we monitored the formation of metalmediated complexes of $\mathrm{H}_{6} \mathrm{CF}$ using SEC-MALS. The three component proteins and their complexes can be partially resolved via SEC, with the largest complexes and proteins eluting first, but SEC does not yield accurate molecular weights for variably shaped proteins like the long rod-shaped chemoreceptor. The MALS data enable the determination of hydrodynamic properties for better estimation of MW. However, MW estimation is not accurate for overlapping peaks or high-MW complexes that elute near the void volume and are highly polydisperse. SEC-MALS was used to monitor formation of complexes of $\mathrm{H}_{6} \mathrm{CF}$ alone (Figure 4) and of functional complexes of $\mathrm{H}_{6} \mathrm{CF}$ with $\mathrm{CheA}$ and $\mathrm{CheW}$ (Figure 5).
Complex formation of $\mathrm{H}_{6} \mathrm{CF}$ alone provided the best means of assessing the effect of metal on the $\mathrm{H}_{6} \mathrm{CF}$ monomer-dimer equilibrium, because $\mathrm{H}_{6} \mathrm{CF}$ dimer and CheA have overlapping peaks (see Figure $5 \mathrm{~B}$ ). We anticipate that binding of $\mathrm{Ni}$ (II) to the $\mathrm{H}_{6} \mathrm{CF}$ His-tag is similar in the presence and absence of CheA and $\mathrm{CheW}$, because ICP-OES indicates 1:1 binding in both cases. As discussed above, incubation of $\mathrm{H}_{6} \mathrm{CF}$ alone with $\mathrm{NiCl}_{2}$ results in sedimentable aggregates. Apparently, these aggregates can become too large to pass the $0.22 \mu \mathrm{m}$ precolumn filter, as the total eluted protein was observed to decrease over the time course of the experiment. Figure 4A shows the overlaid chromatograms from the time course series, all scaled to the same total integrated peak area. The amount of aggregate lost in the precolumn filter (dashed line in Figure 4B) was calculated from the decrease in area with each injection. To quantify the fraction of monomer, dimer, and oligomer, elution time ranges were set at the points of minimum $A_{280}$ between peaks (Figure 4A, gray vertical lines at 10,11.7, 12.8, and 15.5 $\mathrm{min}$ ), and these peak areas were used to calculate the percentage of $\mathrm{H}_{6} \mathrm{CF}$ in monomer, dimer, and oligomer forms (Figure 4B).

SEC-MALS of $\mathrm{H}_{6} \mathrm{CF}$ incubated with $180 \mu \mathrm{M} \mathrm{NiCl}_{2}$ (Figure 4) demonstrates that $\mathrm{Ni}$ (II) stabilizes the $\mathrm{H}_{6} \mathrm{CF}$ dimer. Prior to the addition of $\mathrm{NiCl}_{2}$, the monomer:dimer ratio is approximately 10:1 (Figure 4, red) based on the integrated UV peak area ratio of 5.1:1 (area of the dimer peak divided by 2 gives the dimer concentration). Strikingly, within the minimal time to add metal to the protein and inject it onto the column $(<1$ $\mathrm{min})$, there is a significant decrease in the monomer:dimer ratio to 3.7:1 (Figure 4, orange), which corresponds to a 2.7-fold decrease in this ratio. At remaining time points, both monomer and dimer concentrations continue to decrease in parallel, because of a significant increase in the aggregate fraction (Figure 4B). The system is not at equilibrium, but the monomer:dimer ratio remains in the range of $6-8: 1$, consistent with $\mathrm{Ni}(\mathrm{II})$ stabilization of $\mathrm{H}_{6} \mathrm{CF}$ dimers.

To understand the mechanism of metal-mediated formation of functional complexes, we investigated the assembly kinetics by measuring the onset of kinase activity and sedimentation immediately after combining the $\mathrm{H}_{6} \mathrm{CF}$, CheA, CheW, and 180 

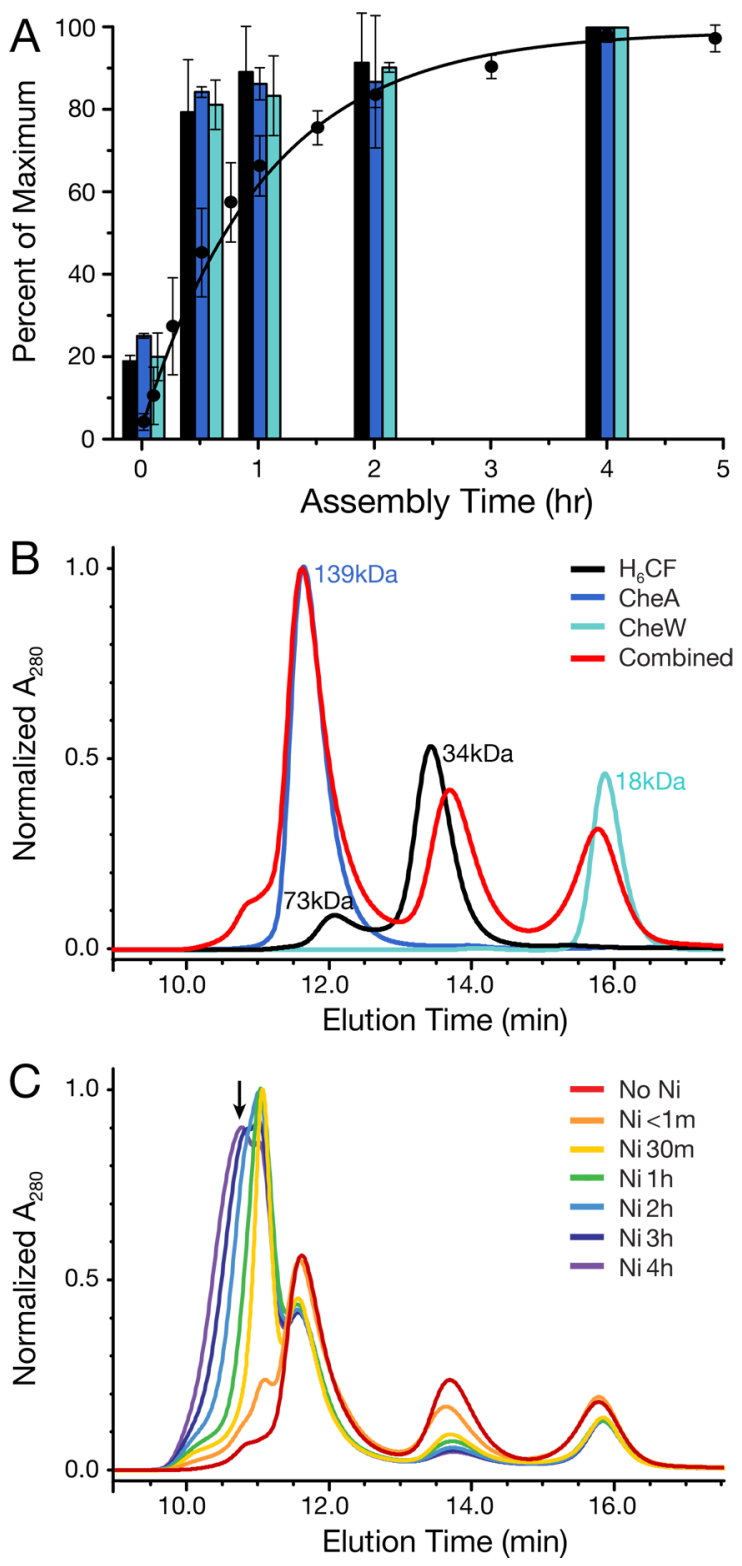

Figure 5. Kinetics of $\mathrm{Ni}(\mathrm{II})$-mediated assembly of $\mathrm{H}_{6} \mathrm{CF}$ ternary complexes. (A) Time course of kinase activity $(\mathbf{O})$ and sedimentation of $\mathrm{H}_{6} \mathrm{CF}$, CheA, and CheW (black, dark blue, and cyan bars, respectively) combined with $180 \mu \mathrm{M} \mathrm{NiCl}_{2}$. The zero time point is before $\mathrm{NiCl}_{2}$ addition. Activity and sedimentation data are normalized to their respective maxima, achieved at $4 \mathrm{~h}$ (maximum total activity of $7.6 \mathrm{~s}^{-1}$, specific activity per bound CheA of $16 \mathrm{~s}^{-1}$, and maximum sedimentations of $27.0 \mu \mathrm{M} \mathrm{H}_{6} \mathrm{CF}$, 5.8 $\mu \mathrm{M}$ CheA, and $13.6 \mu \mathrm{M}$ $\mathrm{CheW}$ ). Activities and sedimentation percentages are averages of two (sedimentation) and four (activity) replicates measured on 2 days; error bars indicate \pm one standard deviation. (B) SEC chromatograms of separately injected $\mathrm{H}_{6} \mathrm{CF}$ (black), CheA (blue), and CheW (cyan) at concentrations used for assembly (Figure 1, legend), as well as a single injection of all three in solution without $\mathrm{NiCl}_{2}$ (red). Molecular masses estimated from multi-angle light scattering (MALS) are indicated and are reasonably consistent with the molecular weights of dimeric CheA (142.7 kDa), dimers and monomers of $\mathrm{H}_{6} \mathrm{CF}(32.7$ $\mathrm{kDa})$, and CheW (18.1 kDa). (C) SEC chromatograms of $\mathrm{H}_{6} \mathrm{CF}$, CheA, and CheW incubated with $\mathrm{NiCl}_{2}$, colored by rainbow according to increasing incubation times. A high-MW complex of $\mathrm{H}_{6} \mathrm{CF}$, CheA, and $\mathrm{CheW}$ (11 min elution time) that forms in low yield in the absence of $\mathrm{NiCl}_{2}$ (0 min sedimentation in panel A and red in panels $\mathrm{B}$ and $C$ ) and in high yield at early incubation times (30 and $60 \mathrm{~min}$ in panel A and yellow and green in panel C) sediments but does not have
Figure 5. continued

high kinase activity. Maximal kinase activity appears to correlate with formation of a higher-MW complex indicated by the arrow (near void volume at a 10.5 min elution time). All chromatograms in each plot are normalized to a value of 1 for the largest peak in the series.

$\mu \mathrm{M} \mathrm{NiCl}$. Assembly with either vesicles ${ }^{24}$ or PEG (unpublished observations) requires incubation at $25^{\circ} \mathrm{C}$ for at least $4 \mathrm{~h}$ before maximal activity is reached. Although the $\mathrm{NiCl}_{2}$ assembly activity similarly achieves maximal activity after $4 \mathrm{~h}$ (Figure 5A), the sedimentation profile shows nearly complete binding (80-90\%) of all three proteins within the first $30 \mathrm{~min}$. Note that complex formation may continue during the $30 \mathrm{~min}$ centrifugation, whereas the kinase activity measurements take $<2 \mathrm{~min}$; therefore, complete binding occurs at 30-60 min. Thus, the kinase activity is only $40-60 \%$ when the CheA and $\mathrm{CheW}$ incorporation is maximal, which suggests that initially the three proteins bind quickly but require conformational changes or rearrangement to reach maximal activity.

We returned to SEC-MALS to monitor complex formation with $\mathrm{NiCl}_{2}$. First, separate injections of the individual proteins demonstrate they are well-resolved and that MALS estimates of the molecular masses are reasonably close to the actual values (Figure 5B and Figure S4): the $32.7 \mathrm{kDa} \mathrm{H}_{6} \mathrm{CF}$ elutes at 13.5 min with an apparent $\mathrm{MW}$ of $34 \mathrm{kDa}$ (black), the $142.7 \mathrm{kDa}$ CheA dimer elutes at 11.5 min with an apparent MW of 139 $\mathrm{kDa}$ (blue), and the $18.1 \mathrm{kDa}$ CheW monomer elutes at $16 \mathrm{~min}$ with an apparent MW of $18 \mathrm{kDa}$ (cyan). These proteins were injected at the concentrations used for metal-mediated assembly ( $30 \mu \mathrm{M} \mathrm{H}_{6} \mathrm{CF}, 12 \mu \mathrm{M}$ CheA, and $24 \mu \mathrm{M}$ CheW). The $\mathrm{H}_{6} \mathrm{CF}$ peak observed at 12 min with an apparent $\mathrm{MW}$ of $73 \mathrm{kDa}$ (black) corresponds to the $65.4 \mathrm{kDa}$ dimer but is hidden under the CheA peak once all proteins are combined. With all three proteins combined and injected at the same concentration as the individual injections (Figure $5 \mathrm{~B}$, red), the two peaks of $\mathrm{H}_{6} \mathrm{CF}$ and $\mathrm{CheW}$ move together slightly, which suggests a possible interaction between the two proteins in solution or on the column. There is also a small shoulder at 11 min, which is likely to be a small amount of ternary complex formation, consistent with the $<15 \%$ sedimentation observed under these conditions for an identical sample $[0$ time in Figure $5 \mathrm{~A}$, which has no $\mathrm{Ni}(\mathrm{II})]$.

To monitor the formation of a complex with time, a large volume was prepared to enable multiple injections of a single sample at different time points. While this experiment imparts a dilution ( $\sim 13$-fold) from injection to elution, which favors protein dissociation, dissociation caused by a 100 -fold dilution of vesicle-assembled arrays is much slower than the time scale of this experiment. ${ }^{24}$

The first changes observed by SEC during complex assembly involve primarily $\mathrm{H}_{6} \mathrm{CF}$. The difference between the no $\mathrm{NiCl}_{2}$ and $<1$ min with $\mathrm{NiCl}_{2}$ injections (Figure $5 \mathrm{C}$, red and orange) is a decrease in $\mathrm{H}_{6} \mathrm{CF}$ peak height and a corresponding increase in the intensity of a high-MW species that elutes at $11.1 \mathrm{~min}$. The latter may consist of only $\mathrm{H}_{6} \mathrm{CF}$ oligomers, because there is no significant change in the intensities of the CheA and CheW peaks. Next, incorporation of CheA and CheW into complexes with $\mathrm{H}_{6} \mathrm{CF}$ appears to be nearly complete in $30 \mathrm{~min}$, based on both the sedimentation data (Figure 5A) showing nearly complete binding at $30-60 \mathrm{~min}$ and the decrease in the intensities of the CheA and CheW SEC peaks (Figure 5C, yellow) with no further changes at longer time points. CheA 

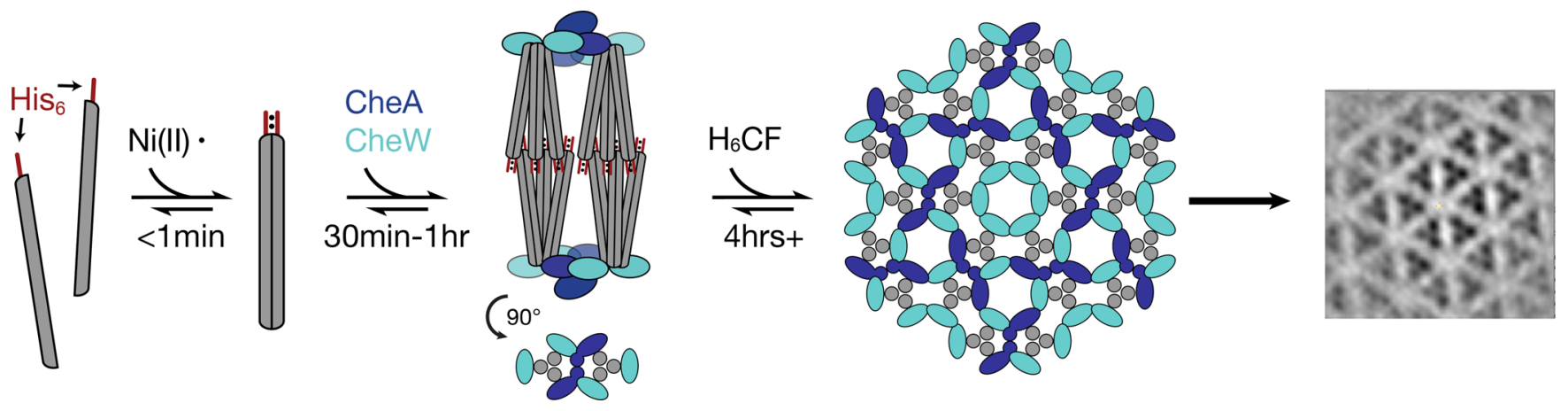

Figure 6. Model of array assembly by $\mathrm{Ni}(\mathrm{II})$-mediated His-tag dimerization. Cartoon representation showing progression of assembly starting with $\mathrm{CF}$ monomers (side view, gray bars) rapidly forming dimers upon $\mathrm{Ni}$ (II) (black dots) binding to CF His-tags (red line). CheA dimers (blue) and CheW monomers (cyan) bind to stabilized $\mathrm{H}_{6} \mathrm{CF}$ dimers to capacity within $30 \mathrm{~min}$ to $1 \mathrm{~h}$. Binding of a CheA dimer and four CheWs drives assembly of a pair of trimers-of-receptor dimers into a core unit, which is likely further stabilized as a sandwich. At longer time points $(\geq 4 \mathrm{~h})$, the assemblies form hexagons and larger arrays with alternating $\mathrm{CheA} / \mathrm{CheW}$ and $\mathrm{CheW}$-only rings.

and $\mathrm{CheW}$ are presumably incorporated into a complex with $\mathrm{H}_{6} \mathrm{CF}$ that elutes as a large SEC peak at $11.1 \mathrm{~min}$. While the elution time is the same as that of the small shoulder seen immediately after the addition of $\mathrm{NiCl}_{2}$ (Figure 5C, orange), this peak is highly polydisperse and thus likely contains a mixture of species with different molecular weights. At longer time points (1-4 h, green to blue to violet, Figure $5 \mathrm{C}$ ), a second peak emerges at an even higher MW (arrow, $10.8 \mathrm{~min}$ ) and the $\mathrm{H}_{6} \mathrm{CF}$ peak continues to decrease to nearly zero intensity. These changes coincide with the assembly reaching maximum kinase activity, as shown in Figure $5 \mathrm{~A}$. The $\mathrm{H}_{6} \mathrm{CF}$, CheA, and CheW peaks remaining at $4 \mathrm{~h}$ are consistent with the assembly conditions: large amounts of free CheA and CheW because these are added in excess and only 20\% free $\mathrm{H}_{6} \mathrm{CF}$, consistent with sedimentation analysis that typically shows $\sim 10-15 \%$ free $\mathrm{H}_{6} \mathrm{CF}$ after assembly.

\section{DISCUSSION}

Here we report a novel method for assembly of the aspartate chemoreceptor cytoplasmic fragment (CF) into nanoarrays through metal-mediated His-tag dimerization and compare these to other in vitro nativelike arrays. Functional complexes of $\mathrm{CF}$, CheA, and CheW form upon addition of specific divalent metals and assemble into an extended hexagonal lattice that exhibits the widely conserved, ${ }^{5,35}$ native $12 \mathrm{~nm}$ center-to-center spacing (Figure 3). Intact chemoreceptor arrays are normally stabilized by a combination of anchoring in the membrane and cytosolic binding of $\mathrm{CheA}$ and $\mathrm{CheW}$ in rings at the membrane-distal cytoplasmic tip of the receptor. In current structural models of the complex, the long ( 200 $\AA)$ cytoplasmic domain has protein-protein interactions with itself, CheA, and CheW only at its membrane-distal end, so the constraints imposed by its transmembrane and periplasmic domains are likely critical to the stability of the array. The necessary membrane-proximal stability to form CF arrays can be achieved with a membrane mimetic (templating vesicles) ${ }^{15}$ or with a sandwich architecture produced with $\mathrm{PEG}^{17}$ or divalent metals (this work). Importantly, all three in vitro preparations with CF yield high CheA occupancy and native stoichiometry (Figure 2C), although PEG arrays have previously been shown to lack the alternating hexagons of CheA observed for in vivo arrays. ${ }^{12}$ Measured CheW stoichiometries of 2 monomers per $6 \mathrm{CF}$ monomers in these assemblies provide further evidence of $\mathrm{CheW}$-only rings that are proposed to provide structural integrity to the array.
Chemoreceptors have been observed to form alternate nonnative structures in the absence or with insufficient quantities of their cytoplasmic binding partners, CheA and CheW. In particular, so-called "zippers" with interdigitation of the receptor cytoplasmic tips have been reported for overexpressed receptors in vivo, ${ }^{4,36}$ reconstituted intact receptors, ${ }^{37}$ and CF assembled on templating vesicles. ${ }^{24} \mathrm{~A}$ more detailed analysis of the overexpressed intact receptors revealed hexagonal packing with $9 \mathrm{~nm}$ center-to-center spacing that is distinct from that of the wild-type $12 \mathrm{~nm}$ arrays observed in both membrane-bound and sandwich architectures. ${ }^{12}$ In this study, we have identified yet another structure formed by CF in the absence of CheA and CheW, double-stranded fibrils. ECT images (Figure S5A) demonstrate that $\mathrm{H}_{6} \mathrm{CF}$ and $\mathrm{NiCl}_{2}$ in the absence of CheA and $\mathrm{CheW}$ produce a mixture of nonspecific aggregates and fibrils with uniform $7 \mathrm{~nm}$ widths but varying lengths (40-105 nm). Interestingly, these fibrils and aggregates are at least partially reversible: addition of $\mathrm{CheA}$ and $\mathrm{CheW}$ after preincubation of $\mathrm{H}_{6} \mathrm{CF}$ with $\mathrm{NiCl}_{2}$ can produce complexes with kinase activity that is $60-80 \%$ of that of normal complexes assembled by adding $\mathrm{NiCl}_{2}$ last (Figure $\mathrm{S} 5 \mathrm{~B}$ ).

In contrast to the non-native "zippers" that form with cytoplasmic tips interdigitated in the center in the absence of sufficient CheA and CheW, "sandwiches" have receptors oriented in the opposite direction: cytoplasmic tips interact with $\mathrm{CheA} / \mathrm{CheW}$ rings on both surfaces of the sandwich, forming hexagonal arrays with the canonical $12 \mathrm{~nm}$ center-tocenter packing. Although sandwiches are not the native architecture for the E. coli aspartate receptor used in this study, similar cytoplasmic arrays exhibiting both $12 \mathrm{~nm}$ hexagonal lattices and sandwich architectures are observed for cytoplasmic chemoreceptors (lacking transmembrane domains) from a variety of bacteria and archaea, including Vibrio cholerae, ${ }^{19}$ Rhodobacter sphaeroides, ${ }^{18}$ and Methanobacterium formicicum. ${ }^{38}$

The observed metal dependence of assembly is consistent with the proposed His-tag dimerization mechanism. The relative efficiency of the divalent metals in promoting active complex formation $[\mathrm{Ni}(\mathrm{II})>\mathrm{Zn}$ (II) $>\mathrm{Co}(\mathrm{II})]$ follows the relative affinities of these metals for peptides containing multiple His residues. ${ }^{39}$ This is consistent with preliminary Xray absorption spectroscopy (XAS) data (H.-T. Huang and M. J. Maroney, unpublished observations), suggesting that the $\mathrm{Ni}(\mathrm{II})$ bound to $\mathrm{H}_{6} \mathrm{CF}$ is coordinated by six ligands, including multiple histidines. Importantly, knowing $\mathrm{Ni}(\mathrm{II})$ is six- 
coordinate and therefore paramagnetic suggests it may be possible to obtain distance constraints with paramagnetic relaxation enhancement NMR experiments involving comparison to the diamagnetic $\mathrm{Zn}$ (II) assembly that has an identical array architecture as determined by ECT (Figure S6). This could provide critical structural information in the overlap region of the sandwich where electron density is lost in ECT (Figure S2)

Characterization of the metal-mediated assembly of CF arrays by activity assays, sedimentation assays, and SEC-MALS allows us to propose a model for the mechanism of this assembly (Figure 6) and yields new insights into the assembly and properties of native chemoreceptor arrays. The fast $(<1$ $\mathrm{min}$ ) initial increase in the dimer fraction (Figure 4) indicates that assembly begins with the stabilization of CF dimers, most likely by metals bridging two His tags. Subsequently, CheA and $\mathrm{CheW}$ are incorporated with metal-stabilized CF dimers into sedimentable complexes. However, binding of CheA and CheW is complete within $30-60 \mathrm{~min}$, forming sedimentable complexes smaller than the fully active complexes that form in $4 \mathrm{~h}$ (Figure 5A,C). While our data cannot distinguish the exact size of these initial smaller complexes, Figure 6 shows one possibility that includes full binding of CheA and CheW into a sandwich of two core units, each containing 12 CFs (two trimers of dimers), bridged by one CheA dimer, and also containing four CheW monomers. It is unclear what changes occur between 1 and $4 \mathrm{~h}$ to yield larger complexes with higher activity that ultimately have the canonical hexagonal architecture. In one SEC-MALS series (Figure 5C), there was a small increase in the level of CF binding, while in another series (not shown), there was a small increase in the level of binding of all three proteins. We propose that building to larger complexes with maximal activity likely involves assembly of core units into hexagons that coalesce to form larger arrays and likely also involves additional binding of some CF, CheA, and/ or CheW to unoccupied sites in the coalesced array, as well as rearrangement of CheA and $\mathrm{CheW}$ into the native pattern that maximizes CheA binding in alternating hexagons of $\mathrm{CheA} / \mathrm{W}^{12}$ and only CheW. In any case, it appears that protein-protein interactions beyond those in the core unit are required for full activity.

The insights from this novel in vitro assembly mechanism may also shed light on how these remarkable arrays form in the cell. Briegel and others ${ }^{12}$ proposed the following model for in vivo array assembly: (1) receptors dimerize, (2) three receptor dimers form a trimer of dimers, (3) pairs of receptor trimers of dimers are bridged by a CheA dimer and bind two CheWs to form the core unit, (4) three core units coalesce to form hexagons containing CheA and $\mathrm{CheW}$, and (5) the array grows through binding of additional core units or of additional CheA/ W-filled hexagons. Our data support the importance of the initial receptor dimerization in the membrane, because metalmediated stabilization of the CF dimer is sufficient to drive array assembly. We see no evidence of formation of discrete trimers of CF dimers in the absence of CheA and CheW and instead observe that CF dimers form various oligomers and large aggregates, consistent with prior observations in vivo. ${ }^{4} \mathrm{We}$ propose that in the absence of a stabilizing membrane or membrane mimetic, $\mathrm{CheA}$ and $\mathrm{CheW}$ are required to mediate assembly of receptor dimers into trimers of dimers. These are then bridged by CheA dimers into core units that also bind four CheWs. This would satisfy all of the receptor binding sites (two receptor-CheA interfaces, four receptor-CheW interfaces, and six receptor-receptor interfaces) and thus prevent non-native interactions that lead to aggregation both in vitro and in vivo. Our data support incorporation of four CheWs into the core unit because there is little additional CheW binding upon assembly of larger arrays. Two of the four CheWs in the core unit are weakly bound (lacking the CheA-CheW proteinprotein interaction) and thus would likely be lost during purification of core complexes with full-length receptors in nanodiscs $^{40}$ (which contained two CheWs per core unit). These weakly bound CheWs are more likely to be retained under excess $\mathrm{CheW}$ conditions as in our CF assembly conditions. It seems likely that the additional two weakly bound CheWs in the core unit would increase the rate of assembly and, as previously suggested, ${ }^{9}$ increase the stability of the array. Finally, we propose that assembly of core units into hexagons is required to achieve maximal kinase activity.

Several important differences are expected between the Histag-mediated assembly of arrays of receptor fragments and in vivo assembly of membrane-bound chemoreceptor arrays. Studies of assembly of CF arrays cannot provide insights into the effects of the missing periplasmic, transmembrane, and HAMP domains, or the effects of ligand binding. ${ }^{41}$ Assembly of core units, hexagons, and arrays likely occurs faster in vivo because of alignment of receptors in the membrane facilitating encounters by two-dimensional diffusion within the plane of the membrane rather than by three-dimensional diffusion. Interestingly, although the cellular concentrations of the E. coli chemotaxis array proteins have been shown to vary significantly with strain and growth conditions, the protein ratios in the cell remain consistent at 2.9 receptors to 1 CheA to $1.2 \mathrm{CheWs}^{42}$ This excess CheA and CheW is similar to the conditions of our His-tag-mediated assembly of CF arrays, containing a ratio of 2.5 CF to $1 \mathrm{CheA}$ to $2 \mathrm{CheWs}$. Although in vitro assembly does not duplicate the crowded conditions in the cell that alter protein diffusion rates and affinities, it may be possible to investigate whether excess $\mathrm{CheA}$ and $\mathrm{CheW}$ promote assembly as previously suggested. ${ }^{12}$

Assembly of large multiprotein complexes in vitro that retain native structure and function is a challenging but essential step in understanding how protein machines operate in the cell. We have demonstrated the value of His-tags to mediate dimerization and stabilize homogeneous, functional assemblies of chemotaxis signaling proteins. This dimerization strategy may prove to be valuable for assembly of other complex systems. Indeed, Cornelissen, van Hest, and co-workers discovered that metal-ion-induced stabilization can be used to stabilize a capsid assembly that is otherwise unstable in the absence of a high negative charge from either encapsulated RNA or low $\mathrm{pH}$. Via the simple addition of divalent metals to the His-tagged cowpea chloric mottle virus capsid protein, capsid structures with native particle size form at neutral $\mathrm{pH}$ and can be used to encapsulate other proteins or drugs. ${ }^{43,44}$ Their model suggests the metal promotes His-tag-to-His-tag interactions that stabilize the large oligomeric capsid structure. His-tag-mediated dimerization is a means of stabilizing protein dimers that is much less perturbing than fusion to a protein dimerization motif. For example, fusion to a leucine zipper (LZ) introduces 30-60 residues, which is more perturbing than a six-residue His-tag and can interfere with assembly of native complexes. Interestingly, fusion of a 45-residue LZ to the chemotaxis receptor CF used in our study restored kinase activation but perturbed the assembly of native complexes with CheA and CheW. The LZ-CF assembled into sandwichlike 
particles in the opposite orientation (two CF layers on the outside of a middle layer of CheA and $\mathrm{CheW}$ ) that prevented formation of the native array. ${ }^{45-47}$ This comparison of LZ- and His-tag-mediated dimerization of the same system demonstrates that using the least perturbing means of stabilization protein interactions can be critical to assembling native complexes. This approach has significant potential for application to other multiprotein systems, for the stabilization of functional complexes with native architecture. His-tags are widely used, and they are easily introduced at many locations within a recombinantly expressed protein. This should make it possible to drive dimerization at a known dimer interface with minimal perturbation to structure or function, for straightforward and accurate in vitro studies of the mechanisms of key processes in the cell.

\section{ASSOCIATED CONTENT}

\section{S Supporting Information}

The Supporting Information is available free of charge on the ACS Publications website at DOI: 10.1021/acs.biochem.7b00698.

Protein sedimentation data for $\mathrm{NiCl}_{2}, \mathrm{ZnCl}_{2}$, and $\mathrm{CoCl}_{2}$ assembly titration series; isosurface comparison of Ni(II)- and PEG-mediated sandwich arrays with intact receptor arrays; data sets of five two-dimensional tomographic slices used to estimate baseplate distances; multi-angle light scattering analysis and molar mass estimations for individually injected $\mathrm{H}_{6} \mathrm{CF}$, CheA, and CheW; partially reversible aggregation and fibril formation of $\mathrm{H}_{6} \mathrm{CF}$ with $\mathrm{NiCl}_{2}$; and structural analysis of $\mathrm{Zn}$ (II)-assembled complexes (PDF)

\section{AUTHOR INFORMATION}

\section{Corresponding Author}

*Department of Chemistry, 122 LGRT, 710 N. Pleasant St., University of Massachusetts at Amherst, Amherst, MA 01003. E-mail: thompson@chem.umass.edu. Telephone: +1 (413) 545-0827.

ORCID $\odot$

Lynmarie K. Thompson: 0000-0002-9447-6776

\section{Author Contributions}

E.R.H. and L.K.T. conceived ideas for the project. E.R.H., W.Y., and A.B. conducted the experiments. All authors analyzed the data. E.R.H. and L.K.T. wrote the manuscript, and all authors have given approval to the final version of the manuscript.

\section{Funding}

This research was supported by National Institutes of Health Grant R01-GM085288. E.R.H. was partially supported by National Research Service Award T32 GM008515 from the National Institutes of Health, as part of the UMass ChemistryBiology Interface Training Program.

\section{Notes}

The authors declare no competing financial interest.

\section{ACKNOWLEDGMENTS}

The authors thank Laura Castellanos for help with initial ICPMS metal measurements and Hsin-Ting (Tiffany) Huang and Michael Maroney for assistance with ICP-OES and for providing XAS data. The authors thank Aruni P. K. K. K. Mudiyanselage for generating the CheA, CheW, and CheY plasmids, Monifa Fahie, Christina Chisholm, and Bib Yang for help in the construction of pTEVCF4Q and Xuni Li and Maryam Kashefi for valuable comments and discussions about the manuscript. SEC-MALS data were obtained at the University of Massachusetts Biophysical Characterization Facility. The authors thank the facility director Lizz Bartlett for all her technical guidance and intellectual input on the early stages of this project that led us to use SEC-MALS. All cryoEM data were collected at the NeCEN facility (Leiden, The Netherlands). The authors especially thank the NeCEN operators Dr. Christoph Diebolder and Dr. Julio Ortiz for expert assistance with data collection.

\section{ABBREVIATIONS}

BCA, bicinchonic acid; CF, cytoplasmic fragment of the E. coli aspartate chemotaxis receptor; DOGS-NTA, 1,2-dioleoyl-snglycero-3-\{[N-(5-amino-1-carboxypentyl)iminodiacetic acid]succinyl\}; DOPC, 1,2-dioleoyl-sn-glycero-3-phosphocholine; ECT, electron cryotomography; ICP-OES, inductively coupled plasma-optical emission spectroscopy; IPTG, isopropyl $\beta$-D-1thiogalactopyranoside; LZ, leucine zipper; PEG, polyethylene glycol 8000; PKB, phosphate kinase buffer; PMSF, phenylmethanesulfonyl fluoride; SDS-PAGE, sodium dodecyl sulfate-polyacrylamide gel electrophoresis; SEC-MALS, size exclusion chromatography-multi-angle light scattering; TEV, tobacco etch virus; XAS, X-ray absorption spectroscopy.

\section{REFERENCES}

(1) Marsh, J. A., and Teichmann, S. A. (2015) Structure, dynamics, assembly, and evolution of protein complexes. Annu. Rev. Biochem. 84, $551-575$.

(2) Alberts, B. (1998) The cell as a collection of protein machines: preparing the next generation of molecular biologists. Cell 92, 291294.

(3) Maddock, J. R, and Shapiro, L. (1993) Polar location of the chemoreceptor complex in the Escherichia coli cell. Science 259, 17171723.

(4) Zhang, P., Khursigara, C. M., Hartnell, L. M., and Subramaniam, S. (2007) Direct visualization of Escherichia coli chemotaxis receptor arrays using cryo-electron microscopy. Proc. Natl. Acad. Sci. U. S. A. 104, 3777-3781.

(5) Briegel, A., Ortega, D. R., Tocheva, E. I., Wuichet, K., Li, Z., Chen, S., Muller, A., Iancu, C. V., Murphy, G. E., Dobro, M. J., Zhulin, I. B., and Jensen, G. J. (2009) Universal architecture of bacterial chemoreceptor arrays. Proc. Natl. Acad. Sci. U. S. A. 106, 17181-17186.

(6) Sourjik, V., and Berg, H. C. (2002) Receptor sensitivity in bacterial chemotaxis. Proc. Natl. Acad. Sci. U. S. A. 99, 123-127.

(7) Sourjik, V., and Berg, H. C. (2004) Functional interactions between receptors in bacterial chemotaxis. Nature 428, 437-441.

(8) Briegel, A., Li, X., Bilwes, A. M., Hughes, K. T., Jensen, G. J., and Crane, B. R. (2012) Bacterial chemoreceptor arrays are hexagonally packed trimers of receptor dimers networked by rings of kinase and coupling proteins. Proc. Natl. Acad. Sci. U. S. A. 109, 3766-3771.

(9) Liu, J., Hu, B., Morado, D. R., Jani, S., Manson, M. D., and Margolin, W. (2012) Molecular architecture of chemoreceptor arrays revealed by cryoelectron tomography of Escherichia coli minicells. Proc. Natl. Acad. Sci. U. S. A. 109, E1481-E1488.

(10) Cassidy, C. K., Himes, B. A., Alvarez, F. J., Ma, J., Zhao, G., Perilla, J. R., Schulten, K., and Zhang, P. (2015) CryoEM and computer simulations reveal a novel kinase conformational switch in bacterial chemotaxis signaling. eLife 4, 1-20.

(11) Sferdean, F. C., Weis, R. M., and Thompson, L. K. (2012) Ligand affinity and kinase activity are independent of bacterial chemotaxis receptor concentration: Insight into signaling mechanisms. Biochemistry 51, 6920-6931.

(12) Briegel, A., Wong, M. L., Hodges, H. L., Oikonomou, C. M., Piasta, K. N., Harris, M. J., Fowler, D. J., Thompson, L. K., Falke, J. J., 
Kiessling, L. L., and Jensen, G. J. (2014) New insights into bacterial chemoreceptor array structure and assembly from electron cryotomography. Biochemistry 53, 1575-1585.

(13) Boldog, T., Grimme, S., Li, M., Sligar, S. G., and Hazelbauer, G. L. (2006) Nanodiscs separate chemoreceptor oligomeric states and reveal their signaling properties. Proc. Natl. Acad. Sci. U. S. A. 103, 11509-11514

(14) Hochuli, E., Döbeli, H., and Schacher, A. (1987) New metal chelate adsorbent selective for proteins and peptides containing neighbouring histidine residues. J. Chromatogr. A 411, 177-184.

(15) Shrout, A. L., Montefusco, D. J., and Weis, R. M. (2003) Template-directed assembly of receptor signaling complexes. Biochemistry 42, 13379-13385.

(16) Besschetnova, T. Y., Montefusco, D. J., Asinas, A. E., Shrout, A. L., Antommattei, F. M., and Weis, R. M. (2008) Receptor density balances signal stimulation and attenuation in membrane-assembled complexes of bacterial chemotaxis signaling proteins. Proc. Natl. Acad. Sci. U. S. A. 105, 12289-12294.

(17) Fowler, D. J., Weis, R. M., and Thompson, L. K. (2010) Kinaseactive signaling complexes of bacterial chemoreceptors do not contain proposed receptor-receptor contacts observed in crystal structures. Biochemistry 49, 1425-1434.

(18) Briegel, A., Ladinsky, M. S., Oikonomou, C., Jones, C. W., Harris, M. J., Fowler, D. J., Chang, Y. W., Thompson, L. K., Armitage, J. P., and Jensen, G. J. (2014) Structure of bacterial cytoplasmic chemoreceptor arrays and implications for chemotactic signaling. eLife 3, e02151.

(19) Briegel, A., Ortega, D. R., Mann, P., Kjær, A., Ringgaard, S., and Jensen, G. J. (2016) Chemotaxis cluster 1 proteins form cytoplasmic arrays in Vibrio cholerae and are stabilized by a double signaling domain receptor DosM. Proc. Natl. Acad. Sci. U. S. A. 113, 1041210417.

(20) Wu, J., Li, J., Li, G., Long, D. G., and Weis, R. M. (1996) The receptor binding site for the methyltransferase of bacterial chemotaxis is distinct from the sites of methylation. Biochemistry 35, 4984-4993.

(21) Kashefi, M., and Thompson, L. K. (2017) Signaling-related mobility changes in bacterial chemotaxis receptors revealed by solidstate NMR. J. Phys. Chem. B, n/a DOI: 10.1021/acs.jpcb.7b06475.

(22) Kapust, R. B., Tözsér, J., Fox, J. D., Anderson, D. E., Cherry, S. Copeland, T. D., and Waugh, D. S. (2001) Tobacco etch virus protease: mechanism of autolysis and rational design of stable mutants with wild-type catalytic proficiency. Protein Eng., Des. Sel. 14, 9931000.

(23) Nørby, J. G. (1988) Coupled assay of $\mathrm{Na}^{+}, \mathrm{K}^{+}$-ATPase activity. Methods Enzymol. 156, 116-119.

(24) Montefusco, D. J., Shrout, A. L., Besschetnova, T. Y., and Weis, R. M. (2007) Formation and activity of template-assembled receptor signaling complexes. Langmuir 23, 3280-3289.

(25) Schneider, C. A., Rasband, W. S., and Eliceiri, K. W. (2012) NIH Image to ImageJ: 25 years of image analysis. Nat. Methods 9, 671-675.

(26) Danev, R., Buijsse, B., Khoshouei, M., Plitzko, J. M., and Baumeister, W. (2014) Volta potential phase plate for in-focus phase contrast transmission electron microscopy. Proc. Natl. Acad. Sci. U. S. A. 111, 15635-15640.

(27) Kremer, J. R., Mastronarde, D. N., and McIntosh, J. R. (1996) Computer visualization of three-dimensional image data using IMOD. J. Struct. Biol. 116, 71-6.

(28) Mastronarde, D. N. (1997) Dual-axis tomography: an approach with alignment methods that preserve resolution. J. Struct. Biol. 120, 343-352.

(29) Nicastro, D., Schwartz, C., Pierson, J., Gaudette, R., Porter, M. E., and McIntosh, J. R. (2006) The molecular architecture of axonemes revealed by cryoelectron tomography. Science 313, 944-948.

(30) Pettersen, E. F., Goddard, T. D., Huang, C. C., Couch, G. S., Greenblatt, D. M., Meng, E. C., and Ferrin, T. E. (2004) UCSF Chimera - A visualization system for exploratory research and analysis. J. Comput. Chem. 25, 1605-1612.
(31) Sprules, T., Green, N., Featherstone, M., and Gehring, K. (1998) Nickel-induced oligomerization of proteins containing 10histidine tags. BioTechniques 25, 20-22.

(32) Boldog, T., Grimme, S., Li, M., Sligar, S. G., and Hazelbauer, G. L. (2006) Nanodiscs separate chemoreceptor oligomeric states and reveal their signaling properties. Proc. Natl. Acad. Sci. U. S. A. 103, $11509-11514$.

(33) Greenswag, A. R., Li, X., Borbat, P. P., Samanta, D., Watts, K. J., Freed, J. H., and Crane, B. R. (2015) Preformed soluble chemoreceptor trimers that mimic cellular assembly states and activate CheA autophosphorylation. Biochemistry 54, 3454-3468.

(34) Swain, K. E., Gonzalez, M. A., and Falke, J. J. (2009) Engineered socket study of signaling through a four-helix bundle: Evidence for a Yin-Yang mechanism in the kinase control module of the aspartate receptor. Biochemistry 48, 9266-9277.

(35) Briegel, A., Beeby, M., Thanbichler, M., and Jensen, G. J. (2011) Activated chemoreceptor arrays remain intact and hexagonally packed. Mol. Microbiol. 82, 748-757.

(36) Lefman, J., Zhang, P., Hirai, T., Weis, R. M., Juliani, J., Bliss, D., Kessel, M., Bos, E., Peters, P. J., and Subramaniam, S. (2004) Threedimensional electron microscopic imaging of membrane invaginations in Escherichia coli overproducing the chemotaxis receptor Tsr. J. Bacteriol. 186, 5052-5061.

(37) Weis, R. M., Hirai, T., Chalah, A., Kessel, M., Peters, P. J., and Subramaniam, S. (2003) Electron microscopic analysis of membrane assemblies formed by the bacterial chemotaxis receptor Tsr. J. Bacteriol. 185, 3636-3643.

(38) Briegel, A., Ortega, D. R., Huang, A. N., Oikonomou, C. M., Gunsalus, R. P., and Jensen, G. J. (2015) Structural conservation of chemotaxis machinery across Archaea and Bacteria. Environ. Microbiol. Rep. 7, 414-419.

(39) Sovago, I., Varnagy, K., Lihi, N., and Grenacs, A. (2016) Coordinating properties of peptides containing histidyl residues. Coord. Chem. Rev. 327-328, 43-54.

(40) Li, M., and Hazelbauer, G. L. (2011) Core unit of chemotaxis signaling complexes. Proc. Natl. Acad. Sci. U. S. A. 108, 9390-9395.

(41) Li, G., and Weis, R. M. (2000) Covalent modification regulates ligand binding to receptor complexes in the chemosensory system of Escherichia coli. Cell 100, 357-365.

(42) Li, M., and Hazelbauer, G. L. (2004) Cellular stoichiometry of the components of the chemotaxis signaling complex. Proc. Natl. Acad. Sci. U.S.A. 186, 3687-3694.

(43) Minten, I. J., Wilke, K. D. M., Hendriks, L. J. A., Van Hest, J. C. M., Nolte, R. J. M., and Cornelissen, J. J. L. M. (2011) Metal-ioninduced formation and stabilization of protein cages based on the cowpea chlorotic mottle virus. Small 7, 911-919.

(44) Van Eldijk, M. B., Schoonen, L., Cornelissen, J. J. L. M., Nolte, R. J. M., and Van Hest, J. C. M. (2016) Metal ion-induced selfassembly of a multi-responsive block copolypeptide into well-defined nanocapsules. Small 12, 2476-2483.

(45) Francis, N. R., Levit, M. N., Shaikh, T. R., Melanson, L. A., Stock, J. B., and Derosier, D. J. (2002) Subunit organization in a soluble complex of Tar, CheW, and CheA by electron microscopy. J. Biol. Chem. 277, 36755-36759.

(46) Francis, N. R., Wolanin, P. M., Stock, J. B., Derosier, D. J., and Thomas, D. R. (2004) Three-dimensional structure and organization of a receptor/signaling complex. Proc. Natl. Acad. Sci. U. S. A. 101, $17480-5$.

(47) Wolanin, P. M., Baker, M. D., Francis, N. R., Thomas, D. R., DeRosier, D. J., and Stock, J. B. (2006) Self-assembly of receptor/ signaling complexes in bacterial chemotaxis. Proc. Natl. Acad. Sci. U. S A. $103,14313-14318$. 